\title{
Cloud Halos: Numerical Simulation of Dynamical Structure and Radiative Impact
}

\author{
MiaO-Ling LU \\ California Institute of Technology, Pasadena, California \\ Robert A. MCClatchey \\ Aerodyne Research, Inc., Billerica, Massachusetts \\ JOHN H. SEINFELD \\ California Institute of Technology, Pasadena, California
}

(Manuscript received 14 September 2001, in final form 9 April 2002)

\begin{abstract}
Significant enhancements in humidity around cumulus clouds, that is, the "cloud halos" observed in many aircraft penetrations, are simulated using a three-dimensional dynamic model. Five case studies show that humidity halos occur mainly near lateral cloud boundaries and also occur at cloud top and base when the cloud dissipates. The humidity halo broadens as the cloud ages and is also broader in the presence of wind shear than in its absence, especially on the downshear side of the cloud. The broadband calculation over the solar spectrum $(0.2-4.0 \mu \mathrm{m})$ shows that the shortwave (SW) heating rate in the halo is about $11 \%-18 \%$ larger than the ambient environmental heating rate. The strongest halo-induced surface SW radiative forcing for all cases studied is about $-0.2 \mathrm{~W} \mathrm{~m}^{-2}$, which is approximately a $0.02 \%$ change from the forcing without a halo.
\end{abstract}

\section{Introduction}

Significant enhancements in humidity above that in the cloud-free atmosphere have been found to occur on the downshear side of cumulus clouds (Malkus 1949, 1954; Ackerman 1958; Telford and Wagner 1980; Radke and Hobbs 1991; Hobbs and Radke 1992; Perry and Hobbs 1996; Kollias et al. 2001). These regions of high humidity, termed cloud or humidity halos, can extend out to substantial distances from the cloud itself. Figure 1 schematically depicts a cloud-halo region.

A number of fundamental issues emerge as a result of the existence of humidity halos: What are the horizontal and vertical extents of halo regions for different classes of cumulus clouds? What is the temporal evolution of the halo relative to the cloud evolution? How does halo development depend on prevailing wind conditions? What effect does the existence of a humidity halo have on radiative transfer in the atmosphere? For example, how do shortwave (SW) absorption and heating for the halo compare with those of the cloud itself and with that of the ambient atmosphere? Detailed numerical simulations of cloud halo development and lifetimes have not been reported previously. Our goal in

Corresponding author address: John H. Seinfeld, California Institute of Technology, 210-41, Pasadena, CA 91125.

E-mail: seinfeld@caltech.edu this paper is to explore the dynamical and radiative aspects of cloud halos through numerical simulation using state-of-the-art dynamic and radiative transfer models.

Some of the early measurements of tropical (trade wind) cumulus were conducted in the Caribbean Sea. Trade wind cumulus patches observed in the Caribbean are roughly $30 \mathrm{~km}$ in diameter and contain many individual 1-2-km cumulus clouds (Malkus 1949, 1954). Wide clear areas typically separate these patches. Early aircraft-based studies of trade wind cumulus emphasized turbulence within clouds and in the surrounding clear air. Malkus found that a region of turbulence extended asymmetrically around a cloud with its maximum in the downshear (and downwind) direction (some confusion over this asymmetry occurs in her paper because of an apparent wind direction definition that is the opposite of the conventional one). She developed a model of a cloud and its turbulent structure that suggests that the cloud grows in the upwind (and upshear) direction and decays on the downwind (and downshear) side. In this way, she speculated that the cloud's influence remains even as the observable cloud decays. The work of Ackerman (1958) extended these concepts by using a much larger aircraft-based experimental program that entailed 379 penetrations of 78 cumulus clouds. Ackerman also found that the cloud develops in the upshear direction and dissipates in the downshear direction, leaving be- 


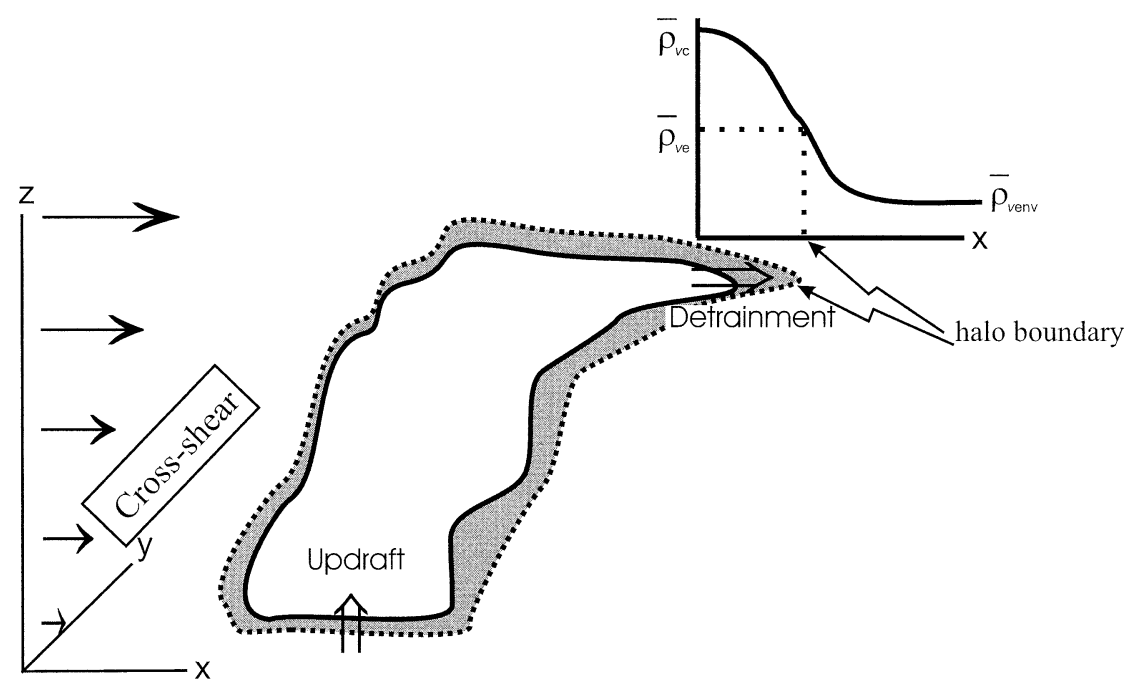

Upshear

Downshear

FIG. 1. Schematic of cloud halo (shaded region). This depiction shows a westerly wind increasing with height. Upshear and downshear are defined relative to the vertical wind shear, average absolute humidity is sketched as a function of the distance from the cloud edge (upper right corner), and $\bar{\rho}_{v c}(z)$ is the mean absolute humidity of the cloud. When the absolute humidity approaches a constant value, it is defined as $\bar{\rho}_{\text {venv }}(z) ; \bar{\rho}_{v e}(z)$ is the $e$-folding absolute humidity calculated by Eq. (3). If there is cloud at an arbitrary height $z$, the cloud halo is defined by that region of the humidity field for which $\bar{\rho}_{v c}(z)>\rho(z)>\bar{\rho}_{v e}(z)$. If there is no cloud at that altitude, the halo is defined by Eq. (4).

hind a region of "cloud influence" characterized by clear-air turbulence. She found time constants of 10-25 min to be significant for development and decay processes. Ackerman may be the first to suggest that a humidity halo might accompany these areas of influence, even going a step further as follows: "If the turbulent regions are 'old' cloud air from which the liquid water has evaporated, they must also be regions of high humidity and consequently preferred areas for new cloud development" (Ackerman 1958). These regions of high humidity do represent preferred areas for new cloud development, as was later shown in the observations of Telford and Wagner (1980). Aircraft measurements of small cumulus by Radke and Hobbs (1991) and Hobbs and Radke (1992) demonstrated that cumulus clouds are surrounded by regions of high humidity out to distances of several cloud radii from the cloud center.

Perry and Hobbs (1996) found significant humidity enhancements in the clear air, particularly downshear of small- to medium-sized (0.4-4.3 km deep) cumulus clouds over the northeast Pacific Ocean near the Washington and Oregon coastlines. The humidity halo was found to broaden with cloud age, and the orientation relative to the vertical wind shear was the most important factor determining the frequency and average size of the halo. For the clouds sampled, humidity halos were found on the downshear, cross-shear, and upshear sides of the clouds $74 \%, 40 \%$, and $36 \%$ of the time, respectively; their average size was largest downshear and smallest upshear. Bretherton and Smolarkiewicz (1989) and Perry and Hobbs (1996) suggested that, in the absence of vertical wind shear, air is detrained from the cloud equally in all directions in the layer where the incloud buoyancy decreases with height. In the presence of vertical wind shear, the clear-air humidity field on the downshear side is enhanced by cloud evaporation in the detrained air while on the upshear side it is limited by the growth of cloud engulfing the detrained air. Recent radar measurements of fair-weather cumuli (Kollias et al. 2001) also showed the moisture gradient to be enhanced far beyond the lateral cloud boundaries.

Radiative transfer in the halo region is a complex issue (Fig. 2). The existence of a humidity halo changes not only the radiation balance of the clear sky adjacent to the cloud but also that of the cloud itself. Enhanced SW absorption exists in the halo relative to that far from the cloud, because of absorption of both the incident solar radiation and the scattered SW radiation from the cloud. Podgorny et al. (1998) computed enhanced column absorption for broken clouds by assuming that the water vapor in the cloud gaps is its saturation value, as opposed to an unsaturated water vapor field generally used in climate models. Prior studies have focused on the enhanced column absorption due to a horizontally 

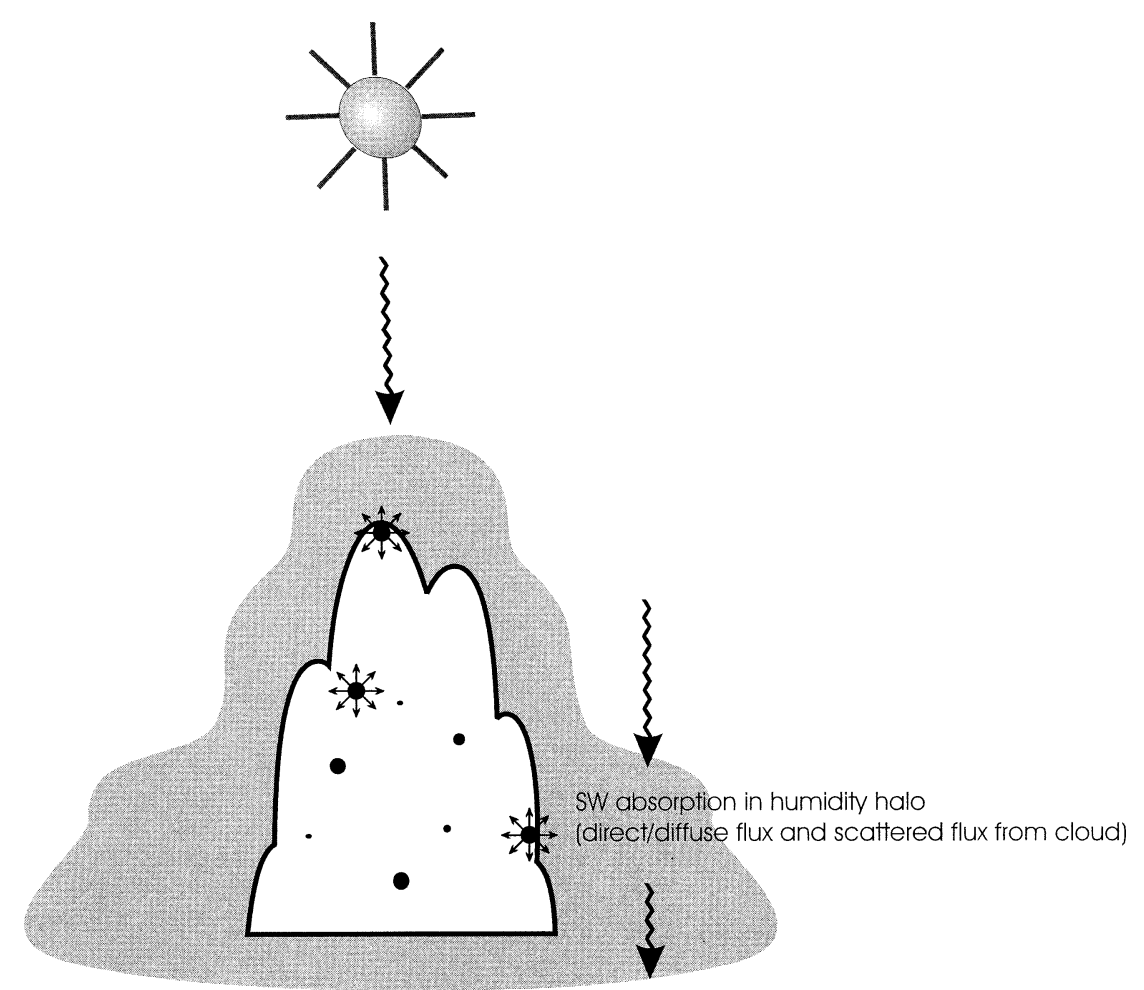

FIG. 2. Schematic of radiative transfer in the cloud halo for a cumulus cloud. The cloud halo absorbs incident solar radiation directly in addition to the scattered radiation from nearby cloud droplets.

homogeneous water vapor layer overlying the cloud top (Davies et al. 1984; Podgorny et al. 1998; Li and Trishchenko 2001), clouds with a water vapor field at its saturation value relative to the drier background (Crisp 1997), and the increase in the background water vapor (Arking 1996). None has considered radiative effects of inhomogeneous three-dimensional water vapor fields associated with clouds beyond their lateral boundaries, below their bases, or above their tops with either measurement or numerical modeling.

In this paper, we present a numerical study of cumulus cloud development based on several case studies, focusing on addressing the following questions: What are the horizontal and vertical extents and time evolution of humidity halos for several generic cloud-forming conditions? Are there features common to humidity halos for different cumulus conditions? By how much does a humidity halo enhance radiative heating in the whole spatial domain, including cloud and halo? Section 2 presents a brief description of the dynamical cloud model and radiative transfer model used. Discussions of several case studies are presented in section 3. Section 4 addresses the radiative effect of the humidity halo.

\section{Dynamic cloud model}

The dynamic model used in this study is the largeeddy simulation (LES) version of the Regional Atmo- spheric Modeling System (RAMS) developed at Colorado State University (Pielke et al. 1992). This Eulerian 3D model is nonhydrostatic and compressible. The prognostic variables include the three velocity components, the Exner function (the pressure variable), the ice-liquid water potential temperature (Tripoli and Cotton 1981), and the total water mixing ratio. The LES implementation uses a " 1.5 th-order" subgrid scheme adapted from Deardorff (1970), which predicts the turbulent kinetic energy in order to evaluate eddy mixing coefficients when using very fine horizontal grid spacing to resolve convective motions. The parameterization of Harrington (1997) is used in RAMS to update the radiative tendency, that is, the temperature change due to radiation. This radiation scheme assumes a two-stream approximation and therefore is only used for cloud simulation (see the discussion about the $3 \mathrm{D}$ radiative transfer model later in the text).

\section{a. Microphysical parameterization}

The standard microphysical scheme in RAMS is a bulk parameterization, featuring a generalized gamma size distribution function for hydrometeors,

$$
n(D)=\frac{N_{t}}{\Gamma(\nu)}\left(\frac{D}{D_{n}}\right)^{\nu-1} \frac{1}{D_{n}} \exp \left(-\frac{D}{D_{n}}\right),
$$


where $N_{t}$ is the total number concentration of individual hydrometeors of diameter $D, \nu$ is the shape parameter, and $D_{n}$ is the characteristic diameter of the distribution. In the pure warm-cloud simulations to be presented here, rainwater number concentration is the only predicted hydrometeor property; rain- and cloud water mixing ratios are diagnosed (Walko et al. 1995).

\section{b. Radiative transfer model}

O'Hirok and Gautier (1998), using a 3D Monte Carlo-based radiative transfer model with high spectral and spatial resolution, investigated solar radiation within a cloudy atmosphere and demonstrated that planeparallel 1D assumptions used in general circulation models can underestimate atmospheric absorption in comparison with a 3D calculation. Wendisch and Keil (1999) and Arking (1996) also show that 3D radiative transfer models are required to perform accurate radiative transfer calculations in the presence of horizontal cloud inhomogeneities.

The spherical harmonic discrete ordinate method (SHDOM; Evans 1993, 1998), an efficient and flexible $3 \mathrm{D}$ atmospheric radiative transfer model that solves the radiative transfer equation to a high degree of accuracy, is employed in the current study. SHDOM can compute unpolarized, monochromatic and broadband (with correlated $k$ distribution; Fu and Liou 1992), shortwave $(0.2-4.0 \mu \mathrm{m})$ and longwave $(4.0-100 \mu \mathrm{m})$ radiative transfer in a vertically inhomogeneous atmosphere. Trautmann et al. (1999) show that spatial patterns of the actinic flux fields calculated by the 2D Monte Carlo method and SHDOM agree closely, to within 1\%-2\% when horizontally averaged. SHDOM enables radiance at any angle; hemispheric fluxes, net fluxes, mean radiances, and net flux convergence can be obtained anywhere in the domain. The source function of the radiative transfer equation is computed on a discrete spatial grid, with the angular variable represented by a truncated series of spherical harmonics. The radiative transfer equation is then integrated along discrete ordinate directions throughout the spatial grid to represent the streaming of photons. The solution algorithm takes advantage of an adaptive grid technique, which automatically places additional grid points during the iteration process in those regions where the optical properties of the medium vary most strongly. Cloud optical properties are computed through Mie theory.

Nongray gaseous absorption by methane, ozone, nitrous oxide, carbon dioxide, and water vapor are treated by the correlated $k$ distribution (Fu and Liou 1992). SHDOM is modified by calculating the $k$ value at each grid cell. In this way, the $3 \mathrm{D}$ water vapor distribution can be considered. The correlated $k$ distribution has six solar bands with boundaries at 0.2, 0.7, 1.3, 1.9, 2.5, 3.5 , and $4.0 \mu \mathrm{m}$. A total of 54 monochromatic calculations $(54 \mathrm{ks})$ are required across these solar bands. For the $\mathrm{SW}$ radiation, gaseous absorption by water vapor
(2500-14 $500 \mathrm{~cm}^{-1}$ ), ozone (in the ultraviolet and visible wave lengths), carbon dioxide (2850-5250 $\left.\mathrm{cm}^{-1}\right)$, and oxygen (A, B, and $\gamma$ bands) are taken into account.

\section{c. Model setup}

It is necessary to initialize several parameters in RAMS prior to simulating cloud development. The cloud droplet distribution must be specified. For this purpose, the cloud droplet gamma distribution in Eq. (1) is used, with shape coefficient $\nu=3.87$ (Chylek and Ramaswamy 1982, their Table 2) and $N_{t}=340$ $\mathrm{cm}^{-3}$ for marine cumulus. A warm-rain process is considered by taking the mean raindrop diameter to be 0.1 $\mathrm{mm}$. We simulate marine cumulus, using the constant sea surface temperatures of 286, 300, and $300 \mathrm{~K}$ for the Oakland, Hawaii, and Barbados cases, respectively (see section 3). The ocean surface albedo is taken to be 0.06 for all radiation wavelengths. A Rayleigh sponge layer is applied adjacent to the top of the domain to damp the reflection of gravity waves from the upper boundary. The upper and lower boundaries are rigid lid and no slip, and the lateral boundary conditions are cyclic in both the $x$ and $y$ directions. The radiation tendency is updated every 10 min using the parameterization of Harrington (1997). Horizontal spacing is $100 \mathrm{~m}$. A stretched vertical grid is used, with a resolution coarsening upward from $40 \mathrm{~m}$ near the surface to a maximum of 1 $\mathrm{km}$ near the top of the domain and with a stretching ratio of 1.1 . There is a total of $60 \times 60 \times 37$ grid cells (except for the Barbados cumulus simulation; see section $3 \mathrm{c}$ ). The simulation time step is $1 \mathrm{~s}$, and the simulated local hour near the time of the minimum solar zenith angle is selected for each case (Table 1). The above-mentioned parameter specifications are applied to all case studies.

In the 3D SHDOM calculations, the solution accuracy for radiative fluxes is set to 0.00001 . There are eight zenith angles and 16 azimuth angles for angular resolution. Adaptive grid splitting criteria for the six solar bands are $1,1,0.1,0.2,0.2$, and $0.2 \mathrm{~W} \mathrm{~m}^{-2}$, above which the grid cell is halved to increase spatial resolution in optically thick media. The solar band calculation uses the delta-M scaling of the medium and the Nakajima and Tanaka (1988) method of computing radiances. The $\mathrm{CO}_{2}, \mathrm{CH}_{4}$, and $\mathrm{N}_{2} \mathrm{O}$ mixing ratios are set to $360,1.6$, and $0.28 \mathrm{ppmv}$, respectively. Molecular Rayleigh scattering as described by Fu and Liou (1992) is included. Air density is taken from RAMS output. The ozone mixing ratio is obtained from McClatchey et al. (1972). The atmospheric profile between the top of the atmosphere (TOA) and the top of the RAMS domain is taken from McClatchey et al. (1972). Periodic boundary conditions are applied for SHDOM, so that photons that exit one side of the grid reenter at the opposite side. 
TABLE 1. Summary of case studies.

\begin{tabular}{|c|c|c|c|c|c|c|c|c|}
\hline Location $^{\mathrm{a}}$ & $\begin{array}{l}\text { Wind } \\
\text { condition }\end{array}$ & $\begin{array}{l}\text { Cloud } \\
\text { lifetime } \\
(\min )\end{array}$ & $\begin{array}{l}\text { Cloud } \\
\text { formation } \\
\text { time } \\
\text { (min) }\end{array}$ & $\begin{array}{l}\text { Cloud } \\
\text { mature } \\
\text { time }^{b} \\
\text { (min) }\end{array}$ & $\begin{array}{c}\text { Max } \\
\text { cloud } \\
\text { depth }^{\mathrm{c}} \\
(\mathrm{km})\end{array}$ & $\begin{array}{c}\text { Max } \\
\text { cloud } \\
\mathrm{LWC}^{\mathrm{c}} \\
\left(\mathrm{g} \mathrm{m}^{-3}\right)\end{array}$ & $\begin{array}{c}\text { Max } \\
\text { in-cloud } \\
\text { updraft } \\
\text { velocity } \\
\left(\mathrm{m} \mathrm{s}^{-1}\right)\end{array}$ & $\begin{array}{l}\text { Solar } \\
\text { zenith } \\
\text { angle } \\
\left({ }^{\circ}\right)\end{array}$ \\
\hline Oakland, CA & No & 28 & 0 & $14-18$ & 0.9 & 1.58 & 3.8 & 51.2 \\
\hline Oakland, CA & Wind shear & 26 & 0 & $12-16$ & 0.7 & 1.24 & 2.9 & 51.2 \\
\hline Kauai, HI & No & 44 & 10 & $18-30$ & 2.7 & 3.11 & 15.2 & 10.6 \\
\hline Kauai, HI & Wind shear & 36 & 10 & $18-20$ & 1.7 & 2.49 & 9.3 & 10.6 \\
\hline Barbados & Windshear & 36 & 14 & $24-26$ & 1.4 & 2.45 & 8.1 & 3.6 \\
\hline
\end{tabular}

a Based on the maximum cloud LWC and maximum in-cloud vertical velocity.

${ }^{b}$ See section 3 for details of the location for each case.

${ }^{c}$ Peak value for the entire simulation and domain.

\section{Simulations of the cloud and associated halo}

To study the properties of cloud halos around different types of cumulus clouds, several cases are simulated. The first case, representing shallow cumulus clouds similar to those observed by Perry and Hobbs (1996; hereinafter termed the "Oakland case"), contains simulations both without wind and with wind shear. The second case represents cumulus clouds typical of Hawaii (hereinafter referred to as the "Hawaii case") for the same wind scenarios. The third case is a Barbados trade wind cumulus

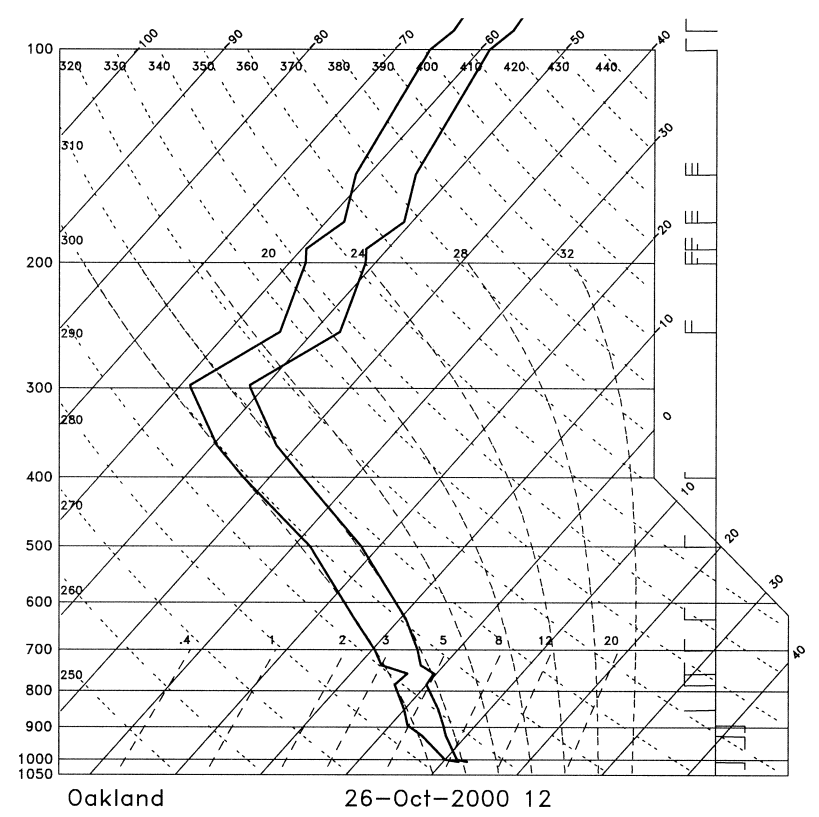

FIG. 3. Skew $T-\log p$ diagram of environmental conditions for a typical shallow cumulus off the northern CA coastline. Temperature and dewpoint temperature profiles are represented by thick lines. The skewed abscissa is temperature $\left({ }^{\circ} \mathrm{C}\right)$, and the ordinate is pressure $(\mathrm{hPa})$. Dotted lines $(\mathrm{K})$ represent dry adiabats. Curved, dashed lines $\left({ }^{\circ} \mathrm{C}\right)$ are pseudoadiabats. Straight-dashed lines $\left(\mathrm{g} \mathrm{kg}^{-1}\right)$ are isopleths of the saturation water vapor mixing ratio. This vertical sounding profile was obtained in Oakland $\left(37^{\circ} 44^{\prime} \mathrm{N}, 122^{\circ} 13^{\prime} \mathrm{W}\right)$ at $1200 \mathrm{UTC}$ 26 Oct 2000 . The north-south wind is arbitrarily set to zero. The sounding profile features an increasing easterly wind with height below $925 \mathrm{hPa}$. (hereinafter termed the "Barbados case") that has been studied previously (e.g., GEWEX 2000). The wind profiles for the Oakland and Hawaii cases are idealized, with only the $u$ component (east-west wind) present so that the simulated moving cloud can be tracked easily.

\section{a. Shallow cumulus off the coast of northern California}

To simulate shallow cumulus clouds typical of those observed by Perry and Hobbs (1996), we chose 26 October 2000 on the basis of satellite imagery that showed numerous cumulus clouds off the coast of northern California. The closest radiosonde site is Oakland, California, from which the model is initialized with the horizontally homogeneous composite sounding shown in Fig. 3.

Similar to the approach used by Kogan (1991), a cumulus cloud is triggered by imposing a horizontally Gaussian-shaped perturbation $\theta^{\prime}$ on the potential temperature in the center of the domain. This impulse, which is assigned sinusoidal variation in the vertical, is effectively $1-\mathrm{km}$ wide and is confined to the lowest 2 $\mathrm{km}$ :

$\theta^{\prime}=0.1 \exp \left[-\frac{\left(x-x_{0}\right)^{2}+\left(y-y_{0}\right)^{2}}{R^{2}}\right] \sin ^{2}\left(\frac{\pi z}{H}\right)$,

where $(x, y)$ and $z$ represent the horizontal and vertical coordinates, respectively; $\left(x_{0}, y_{0}\right)$ is the horizontal location of the central axis; $R$ is an effective perturbation radius; and $H$ is the depth. In this case, $\left(x_{0}, y_{0}\right)=(3$ $\mathrm{km}, 3 \mathrm{~km}), R^{2}=1 \mathrm{~km}^{2}$, and $H=2 \mathrm{~km}$. This warmer area is also initially humidified by a $1 \mathrm{~g} \mathrm{~kg}^{-1}$ water vapor mixing ratio excess below $988 \mathrm{hPa}$ to accelerate cloud formation; when the same simulation was repeated without this humidity perturbation, no cloud formed. The initial sounding is probably not sufficiently moist for clouds to form spontaneously without such a perturbation.

We consider first the case with no mean horizontal wind. The cloud is formed immediately upon starting the simulation. The cumulus reaches its mature stage at 

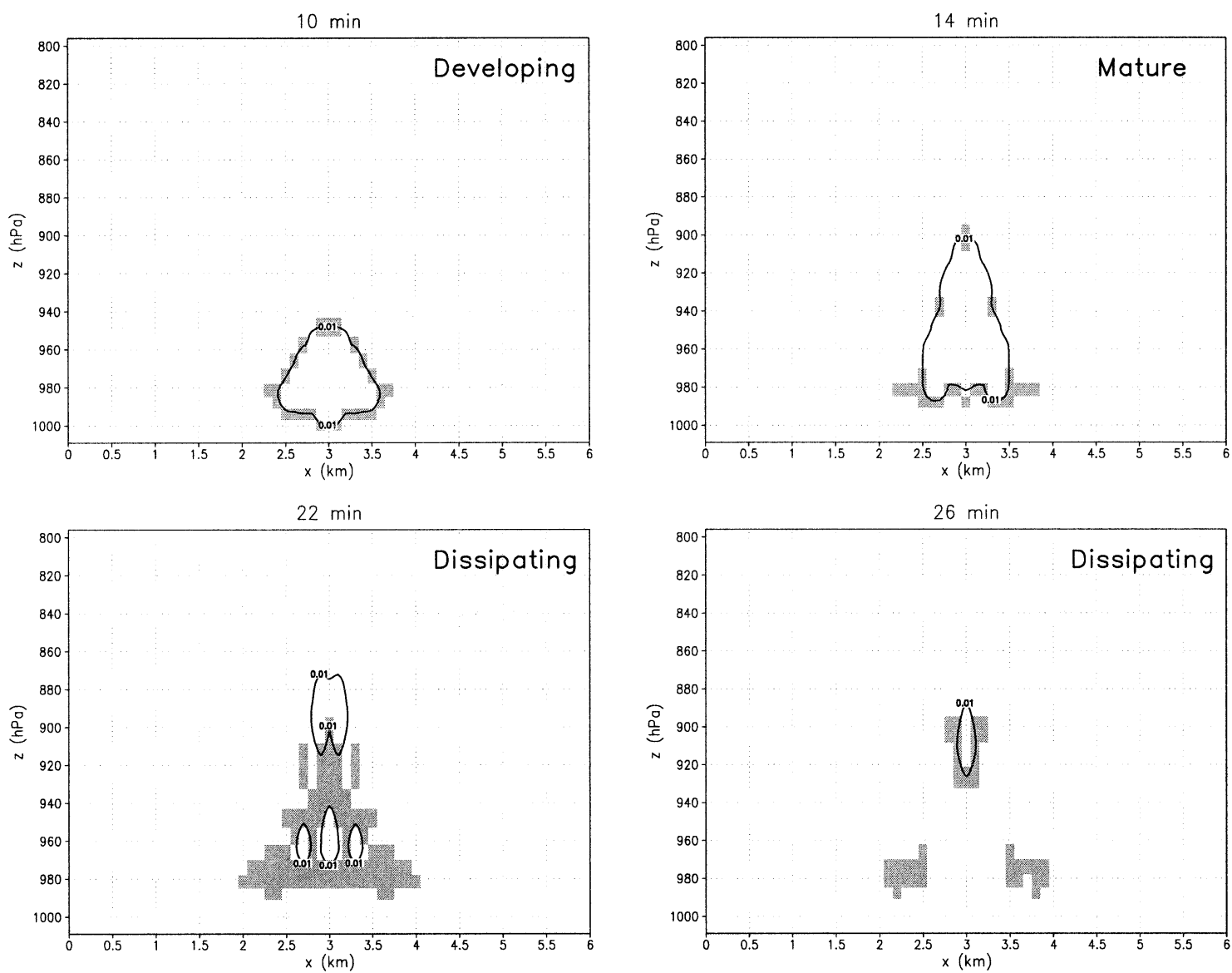

FIG. 4. Simulated development of shallow cumulus off the northern CA coast near Oakland in the absence of wind, for several selected time stages. The contour represents a cloud LWC of $0.01 \mathrm{~g} \mathrm{~m}^{-3}$, chosen to define the cloud boundary. The shaded region outside the cloud boundary, defined to be the cloud halo, is where the absolute humidity exceeds the $e$-folding water vapor density (see Fig. 1).

14 min (Fig. 4), at which time it has a maximum incloud vertical velocity of $3.8 \mathrm{~m} \mathrm{~s}^{-1}$, and then starts to dissipate after $18 \mathrm{~min}$ when the maximum cloud liquid water content (LWC) attained is $1.58 \mathrm{~g} \mathrm{~m}^{-3}$. The cloud lifetime for this case is $28 \mathrm{~min}$, which is typical for small cumulus. The cloud has a virtually symmetric circulation pattern with an updraft core surrounded by downdrafts. The slight asymmetry in the cloud and halo distribution is the result of nonuniform radiative heating in the horizontal.

To measure the horizontal extent of the enhanced humidity around the cloud at a given height, we follow Perry and Hobbs (1996) and represent the humidity in the halo region as decaying exponentially from the average absolute humidity in the cloud at that height, $\bar{\rho}_{v c}(z)$, to the background humidity far from the cloud, $\bar{\rho}_{\text {venv }}(z)$. In doing so, we arbitrarily define the absolute humidity at the outer edge of the halo based on the $e$ folding decay of the profile, as schematized in Fig. 1:

$$
\rho_{v e}(z)=\bar{\rho}_{v c}(z)-\left\{\left[\bar{\rho}_{v c}(z)-\bar{\rho}_{\text {venv }}(z)\right]\left(1-e^{-1}\right)\right\} \text {. }
$$

The humidity halo is then the region in which the absolute humidity around the cloud exceeds the $e$-folding value $\rho_{v e}(z)$. The average is performed along the horizontal axis (i.e., the $x$ axis in this paper) at each altitude. In the current simulation, the grid points satisfying ( $x$, $y)=(200 \mathrm{~m}, 200 \mathrm{~m})$ are used as the far-ambient reference column, near which the atmospheric properties are close to being horizontally uniform. In addition to the halo near the cloud lateral boundaries, evident humidified regions exist above the cloud top or beneath the cloud base in the simulation. In these regions, after the cloud fully dissipates, there is no reference value $\bar{\rho}_{v c}(z)$. Meanwhile, the absolute humidity at arbitrary $z$ fluctuates, especially in the presence of wind shear. Therefore, to have a uniform definition of the humidity halo region under all conditions when the averaged cloud LWC at arbitrary $z$ is zero, we use $\bar{\rho}_{v}(z)$, the horizontally averaged (along the $x$ axis) absolute humidity. Thus, the humidity halo is defined when

$$
\rho_{v}(z)>\bar{\rho}_{v}(z), \quad \text { and } \quad \frac{\rho_{v}(z)-\bar{\rho}_{v}(z)}{\bar{\rho}_{v}(z)}>0.05 .
$$

The value of 0.05 is used to avoid noise in the humidity data. Based on the definition given above, $x-z$ sections 
of the humidity halo region in Fig. 4 consist of the shaded grid boxes outside the cloud in this figure, which depicts the entire simulated cloud evolution. The humidity halo occurs mainly at the lower cloud lateral region and appears to be below the cloud base when the bottom of the cloud dissipates. Note that the humidity halo surrounds the cloud for the entire cloud life and broadens during cloud dissipation. Perry and Hobbs (1996) found that the width of the humidity halo is closely related to the age of the cloud, with older clouds tending to exhibit enhanced humidity out to distances significantly greater than do younger clouds; the humidity halo gradually broadens with time and is widest when the cloud dissipates.

We now add a vertical wind shear, as shown in the sounding profile (Fig. 3), to the previous simulation. Because of the wind shear, the cloud, which generally moves with the horizontal wind, is no longer symmetric (Fig. 5). The maximum in-cloud vertical velocity and LWC are smaller than in the absence of wind, and the simulated cloud life is slightly shorter at $26 \mathrm{~min}$. This simulation basically conforms with the conceptual model of cloud growth proposed by Ackerman (1958) and Telford and Wagner (1980), depicting a cumulus cloud as consisting of quasi-static turbulent entities that grow on the upshear side and decay on the downshear side. Evaporation of cloud droplets on the downshear side humidifies the clear air there while the growth of new cumulus turrets limits the humidity modification on the upshear side. The humidity halo occurs mainly in the lower-cloud lateral regions but is more widely distributed vertically than in the absence of wind. The simulation clearly shows that the halo is broader on the downshear side than on the upshear side (e.g., 14 and 22 min in Fig. 5), is also broader than in the absence of wind, and widens with time. The vertical extent of the humidity halo parallels that of the cloud itself. After the cloud dissipates, a significant region with increased humidity remains.

\section{b. Convective cumulus (Hawaii)}

According to Wang and Chen (1998), trade wind conditions occur in the vicinity of the Hawaiian Islands about $70 \%$ of the year. Their maximum incidence is in August, when they occur $92 \%$ of the time. These trade winds are a reflection of a subtropical high pressure center located north of the Hawaiian Islands near $45^{\circ} \mathrm{N}$, $150^{\circ} \mathrm{W}$. Associated with this subtropical high is the socalled trade wind inversion, which produces a "lid effect" that prevents vertical motion from penetrating this inversion. This strong inversion, caused by subsiding air over the North Pacific Ocean, limits clouds to below $2-3 \mathrm{~km}$ in height where the temperatures are about $10^{\circ} \mathrm{C}$. A typical August inversion is located near $2.2 \mathrm{~km}$, according to $\mathrm{Li}$ and Chen (1999), and trade wind velocities are generally in the range of 6-9 $\mathrm{m} \mathrm{s}^{-1}$ out of the eastnortheast (Chen and Nash 1994). The magnitude of the
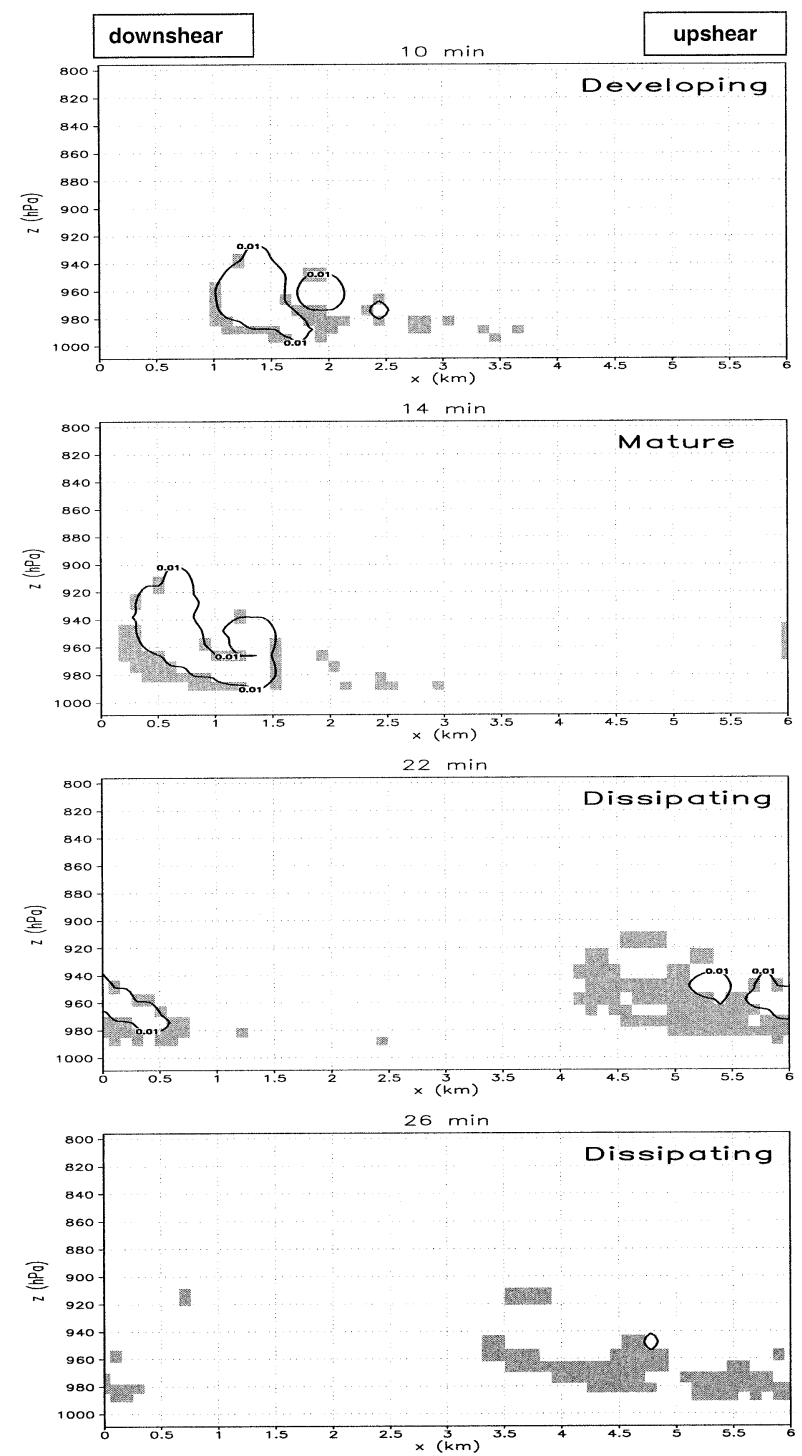

FIG. 5. Same as Fig. 4 but in the presence of the wind shear shown in Fig. 3.

inversion is about $3.6 \mathrm{~K}$. The surface water vapor mixing ratio in the marine boundary layer is about $14.5 \mathrm{~g} \mathrm{~kg}^{-1}$.

According to Takahashi (1977), typical Hawaiian cumulus cloud bases are approximately $0.5 \mathrm{~km}$ above sea level. He indicates that a cloud top of $2.2 \mathrm{~km}$, when the base is at $0.5 \mathrm{~km}$, represents a critical height for the initiation of rain. The trade wind zone typically contains both isolated cumulus clouds and "cloud lines." Individual cumulus clouds are typically $1-2 \mathrm{~km}$ in diameter. When showers occur, their duration averages about 18 min, ranging from 10 to $30 \mathrm{~min}$. Warner (1977), reporting on small marine cumulus off the coast of Australia, describes cloud liquid water and vertical motion that have lifetimes of 20-60 min. He also notes the existence of a persistent strong updraft on the upshear 


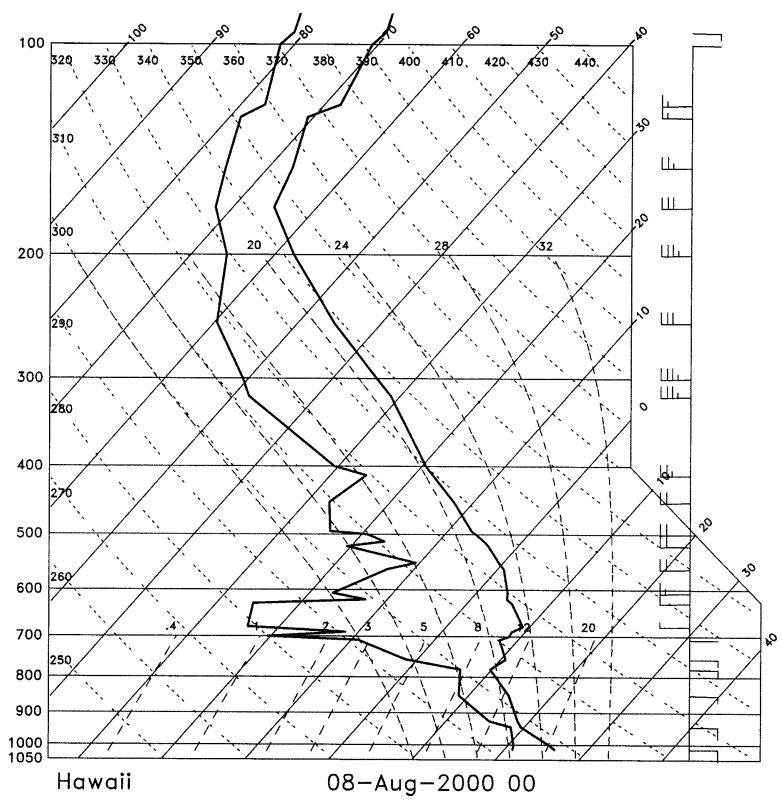

FIG. 6. Skew $T-\log p$ diagram of environmental conditions for a typical cumulus near HI. The description of the lines and ordinates is as in Fig. 3. This vertical sounding profile was observed at Lihue on Kauai, HI $\left(21^{\circ} 59^{\prime} \mathrm{N}, 159^{\circ} 21^{\prime} \mathrm{W}\right)$, at 0000 UTC 8 Aug 2000 . The north-south wind is arbitrarily set to zero. The sounding profile features a decreasing easterly wind with height up to $700 \mathrm{hPa}$, overlain by an increasing westerly wind with height in the cloud layer.

side of the clouds, identifying this $10-15$ min phenomenon with the cloud development phase.

Hawaiian cumulus clouds bear a relationship to largescale stratocumulus "patches" and/or cloud lines moving in the easterly trade winds (Austin et al. 1996). These cloud patches develop in the trade wind flow downstream of the large shallow stratocumulus cloud mass that covers much of the northeastern Pacific Ocean between Hawaii and California. Cloud pictures from polar-orbiting and geostationary satellites clearly show these cloud fields and the frequent patches containing many individual cumulus cells as the Hawaiian Islands are approached.

A convective cumulus cloud is simulated based on the sounding profile shown in Fig. 6, taken in Lihue, Kauai, Hawaii, on 8 August 2000 and selected based on satellite imagery. The convective potential energy in this situation favors deeper convection than in the Oakland case. We impose an initial perturbation below $500 \mathrm{~m}$ in the central region of the domain that is $1 \mathrm{~km}$ wide and is described by Eq. (2) with $H=0.5 \mathrm{~km}$. The domain below $997 \mathrm{hPa}$ is initially humidified by $1 \mathrm{~g} \mathrm{~kg}^{-1}$ in water vapor mixing ratio to expedite cloud formation. The simulated convective cloud and its halo in the absence of wind are shown in Fig. 7. The simulated Hawaii cloud properties are shown in Table 1. This case, as anticipated from the sounding profile, has larger maxima for the updraft velocity, cloud depth, and cloud LWC than the previous case. The halo occurs near the lateral cloud boundaries and is spread out over the cloud depth during the mature stage. Then, dissipation of the upper and middle portion of the cloud leaves a significantly humidified region above the cloud top in the center of the domain. The cloud basically broadens with time.

In the presence of wind shear (Fig. 6), the cloud forms at $10 \mathrm{~min}$ and moves rapidly with the easterlies in the cloud layer (Fig. 8). The simulated bulk cloud properties for the Hawaii cumulus with wind shear (Table 1) are consistent with the measurements reported by Takahashi (1977) for cumulus clouds in the vicinity of Hawaii. As expected, the horizontal extent of the simulated humidity halo is larger on the downshear side than on the upshear side and also increases with time. Dissipation of the cloud at the downshear side leaves a broad humidity halo region, which, as also seen in the Oakland case, is broader in the presence of wind shear than in the absence of wind.

\section{c. Trade wind cumulus (Barbados)}

Fair-weather cumuli play an important role in regulating the vertical structure of water vapor in the lowest $2 \mathrm{~km}$ of the atmosphere over vast areas of the oceans. Recent radar observations (Kollias et al. 2001) of marine fair-weather cumuli near Florida also show enhanced moisture extending far beyond the cloud lateral boundaries. For our third case study, we conduct a simulation of shallow cumulus convection similar to that studied in the model intercomparisons in the Global Cloud Systems Study (GCSS) Working Group 1 (GEWEX 2000). The sounding profile (Fig. 9), measured during the Barbados Oceanographic Meteorological Experiment (BOMEX; Davidson 1968), was selected for representing a typical trade wind boundary layer. The simulation is carried out on a $60 \times 60 \times 75$ grid cell configuration with 100-m grid spacing in the horizontal and 40-m spacing in the vertical. The domain is thus $6 \mathrm{~km}$ by 6 $\mathrm{km}$ in area and $3 \mathrm{~km}$ deep. A time step of $1 \mathrm{~s}$ is used over the entire simulation.

Three distinct layers can be observed from the initial vertical profiles of $\theta$ (potential temperature) and $r_{v}$ (water vapor mixing ratio): a well-mixed layer up to $500 \mathrm{~m}$, a conditionally unstable layer from 500 to $1500 \mathrm{~m}$, and an inversion above that (Fig. 9). The simulation conditions are the same as described earlier, except that the sensible and latent heat fluxes at the surface are now prescribed as $\left\langle w^{\prime} \theta^{\prime}\right\rangle=8 \times 10^{-3} \mathrm{~K} \mathrm{~m} \mathrm{~s}^{-1}$ and $\left\langle w^{\prime} r_{v}^{\prime}\right\rangle=5.2 \times 10^{-3}$ $\mathrm{m} \mathrm{s}^{-1}$, where $w$ is the vertical velocity. The prime denotes deviations from the domain average, indicated by \langle\rangle . The momentum fluxes are prescribed by

$$
\begin{aligned}
& \left\langle u^{\prime} w^{\prime}\right\rangle=-u\left(u^{* 2}\right) / \sqrt{\left(u^{2}+v^{2}\right)} \text { and } \\
& \left\langle v^{\prime} w^{\prime}\right\rangle=-v\left(u^{* 2}\right) / \sqrt{\left(u^{2}+v^{2}\right)},
\end{aligned}
$$

where $u^{*}=0.28 \mathrm{~m} \mathrm{~s}^{-1}$ and the velocities are averaged from the lowest two levels in the model. The GCSS simulation of trade wind cumulus was conducted by imposing numerous random perturbations in the do- 

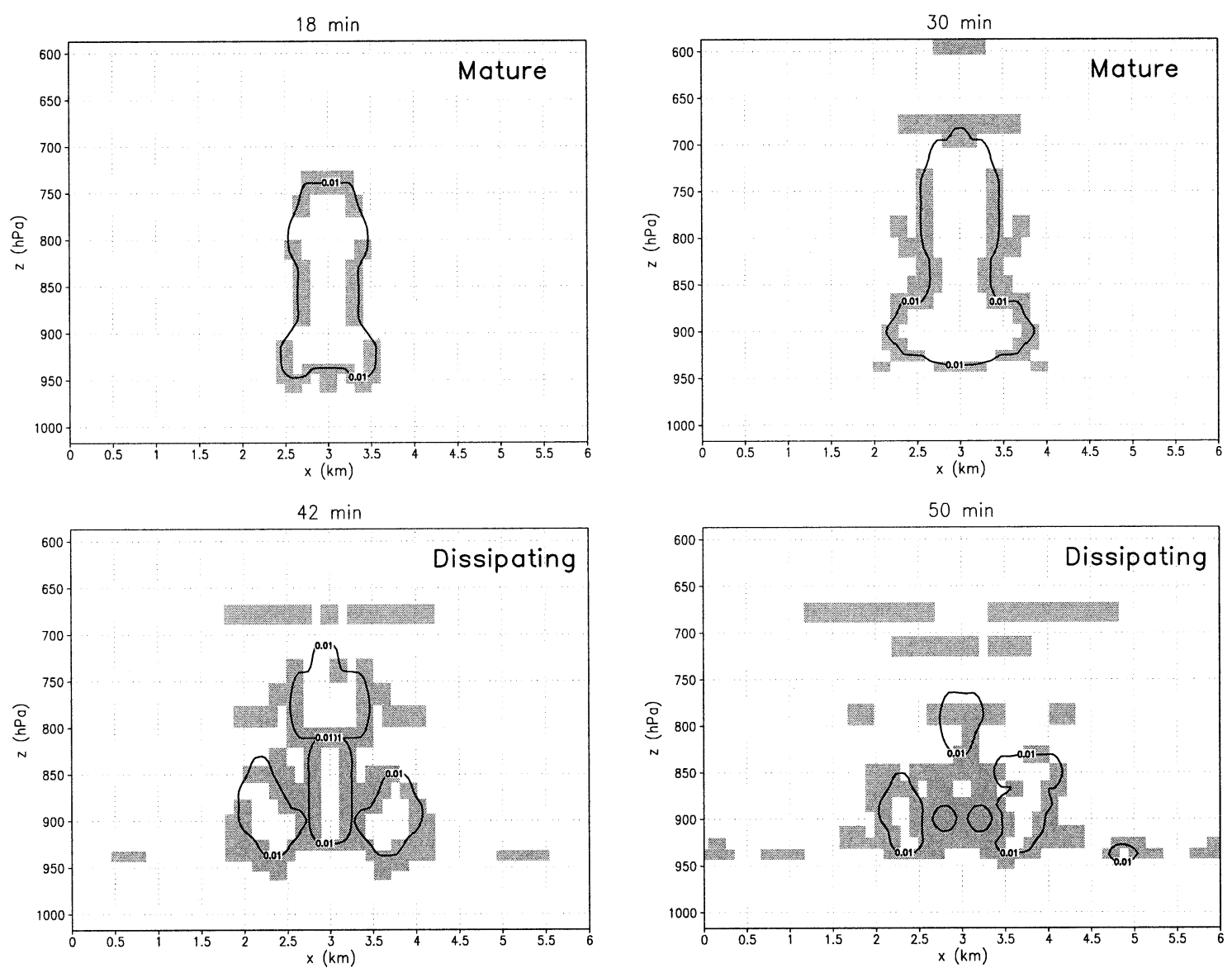

FIG. 7. Same as Fig. 4 but for cumulus cloud near HI in the absence of wind.

main, a technique that produced many cumulus clouds. To produce a single isolated cumulus cloud, an initial perturbation similar to that described in section $3 \mathrm{a}$ is applied, in which $H=360 \mathrm{~m}$ and the domain below $999 \mathrm{hPa}$ is initially humidified by $1 \mathrm{~g} \mathrm{~kg}^{-1}$ in the water vapor mixing ratio to expedite cloud formation.

The simulated fair-weather cumulus cloud properties are in Table 1, and the simulated results are shown in Fig. 10. The cloud has a circulation pattern of an incloud updraft core, with a maximum vertical velocity of $8.1 \mathrm{~m} \mathrm{~s}^{-1}$ at $24 \mathrm{~min}$, and a narrow downdraft region at the downshear side (not shown). Jiang and Cotton (2000) reported simulation results that showed a maximum cloud water mixing ratio of $1.6 \mathrm{~g} \mathrm{~kg}^{-1}$ and a maximum vertical velocity of $3 \mathrm{~m} \mathrm{~s}^{-1}$, both averaged over the cloud updraft region. Our maximum vertical velocity and cloud water mixing ratio are one-point values inside the cloud; therefore, we expect them to be larger than the updraft-region-averaged values in Jiang and Cotton (2000). Radar observations in Miami, Florida, for fair-weather cumuli (Kollias et al. 2001) showed a maximum vertical velocity of $6 \mathrm{~m} \mathrm{~s}^{-1}$ with a smaller cloud depth than in our simulation (i.e., 700 vs 1400 $\mathrm{m})$. We can expect the current simulation to have a higher vertical velocity because the modeled cloud developed much deeper than that which Kollias et al. (2001) observed. The humidity halo exists initially near the lower portions of the lateral cloud boundaries and broadens with time. When the cloud starts to dissipate at the downshear side, halo regions appear both at the lateral cloud boundaries and above the cloud top. A broad halo remains after the cloud is totally dissipated.

\section{d. Summary of case studies}

A summary of the simulated cloud properties of these case studies is given in Table 1 . From the above five simulations, we can conclude that cloud halos appear at the lower cloud lateral regions in the early cloud stages and then start to spread vertically. The vertical extent of the humidity halo parallels the associated cloud depth. A deeper cloud, such as in the Hawaii case, favors a more vertically extensive halo. When the upper or lower portion of the cloud dissipates, the humidity halo appears above the cloud top or beneath the cloud base, respectively. The halo broadens with cloud age. The presence of wind shear can result in a nonsymmetric humidity halo, broader downshear of the cloud than 

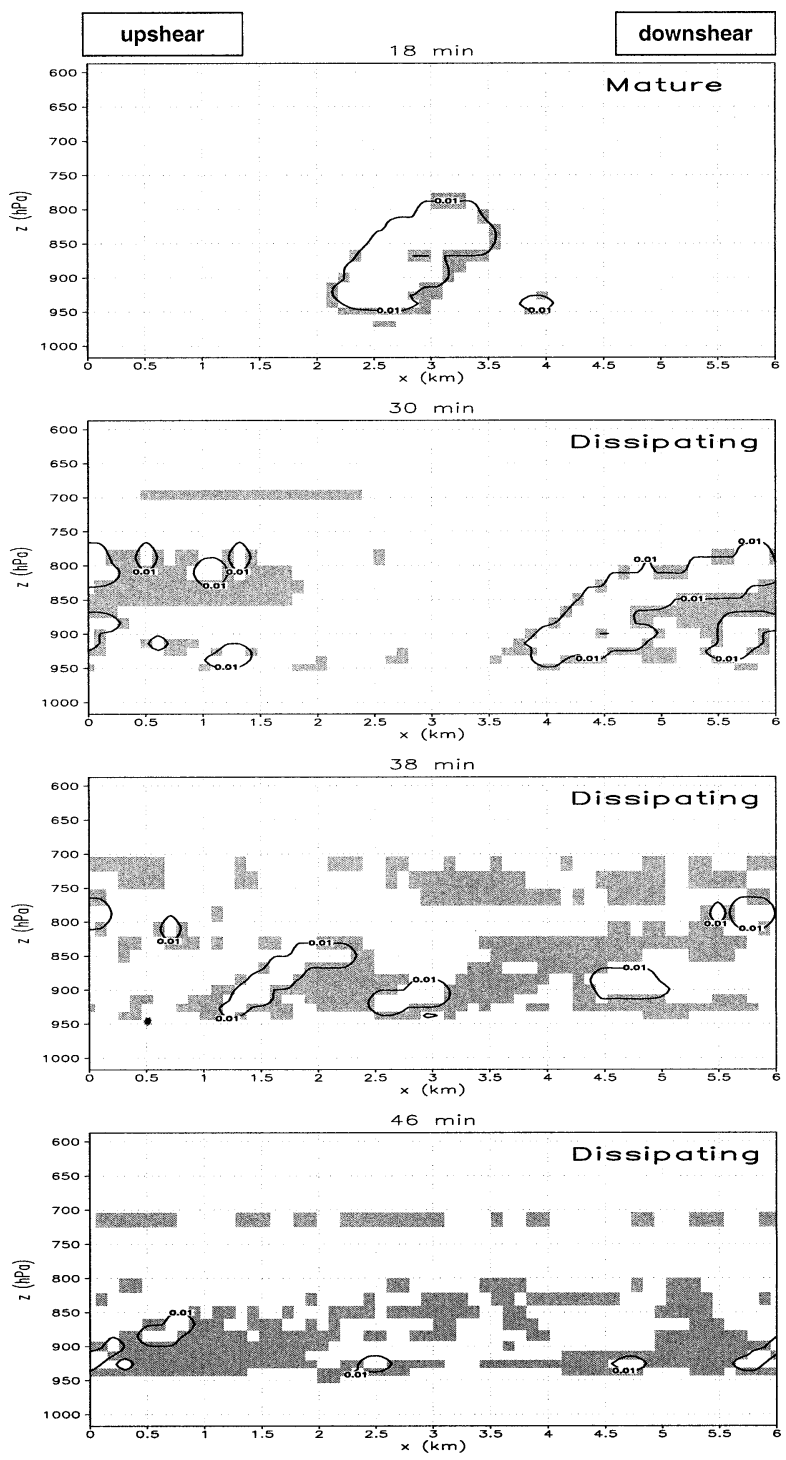

FIG. 8. Same as Fig. 7 but in the presence of the wind shear shown in Fig. 6.

upshear of it. Because of the difficulty of choosing or following a particular cross-shear 2D slice of a moving cloud at each time step, we have not studied cross-shear results in this paper.

\section{Radiative effects of cloud halos}

\section{a. Net downward fluxes}

To study the radiative effect of the humidity halo, we perform 3D radiative calculations using SHDOM. Because SHDOM is very efficient for a $2 \mathrm{D}$ medium but is computationally prohibitive when applied to a realistic 3D cloud field, we decided to use a 2D $(x-z)$ slice of RAMS simulation data in the central domain for the radiation calculation, effectively assuming that the cloud is homogeneous in the $y$ direction. The radiation calculation is

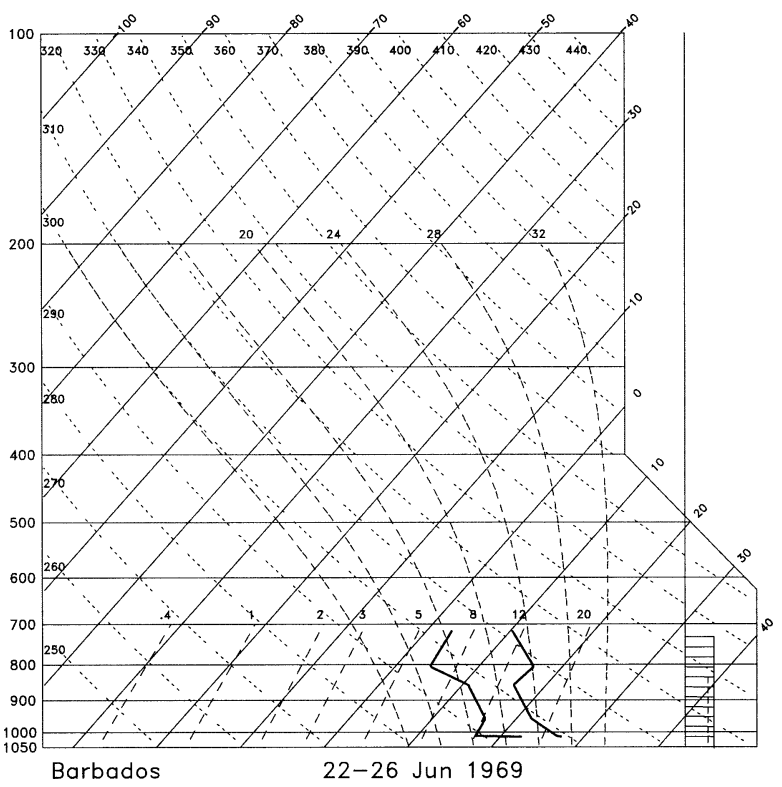

FIG. 9. Skew $T-\log p$ diagram of environmental conditions for a Barbados trade wind cumulus cloud (data were available online at http://www.knmi.nl/ siebesma/gcss/bomexcomp.append.html). The description of the lines and ordinates is as in Fig. 3. The simulation date is 4 Aug 2000.

performed at 4-min intervals. Figure 11 displays the vertical profile of the temporally (over the cloud lifetime) and spatially (over the $x$ axis) averaged net downward radiative flux for all cases. The decrease of the net downward flux averaged over the cloud column (as illustrated in Fig. 12), between the cloud top and the base, is a result of cloud extinction. However, the cloud-column averaging and the slant of the sun's rays cause the flux to increase closer to the surface. As illustrated in Fig. 12, by comparing the two levels, $z_{i}$ and $z_{i+1}$ where $z_{i+1}$ is higher than $z_{i}$, we see that a larger portion of the direct solar flux comes from the surrounding atmosphere, not attenuated by the cloud, at level $z_{i}$ rather than at level $z_{i+1}$. Therefore, in Fig. 11 for the Barbados case in which the solar zenith angle is close to zero, the flux does not increase from the cloud base to the surface, whereas for the Hawaii case with a higher cloud base than the Oakland case, this increase of flux begins at a higher altitude than in the latter case. The net downward flux averaged over the halo columns, rather than decreasing with increasing pressure as in the clear sky, instead increases with increasing pressure in the presence of the cloud. The vertical profile of the net downward flux in the halo shows a trend opposite to that in the cloud from the surface up to above the cloud top. In the lower part of the halo region, the lower-lying of the peaks of the net downward flux is collocated with the minimum in the cloud region, and the multiple peaks are the results of cloud patches formed during the cloud dissipation. If there were no clouds, the water vapor absorption would decrease the net downward flux passing through the halo layer. Therefore, the results illustrate the influence of cloud scattering on the radiative properties of the cloud-edge en- 

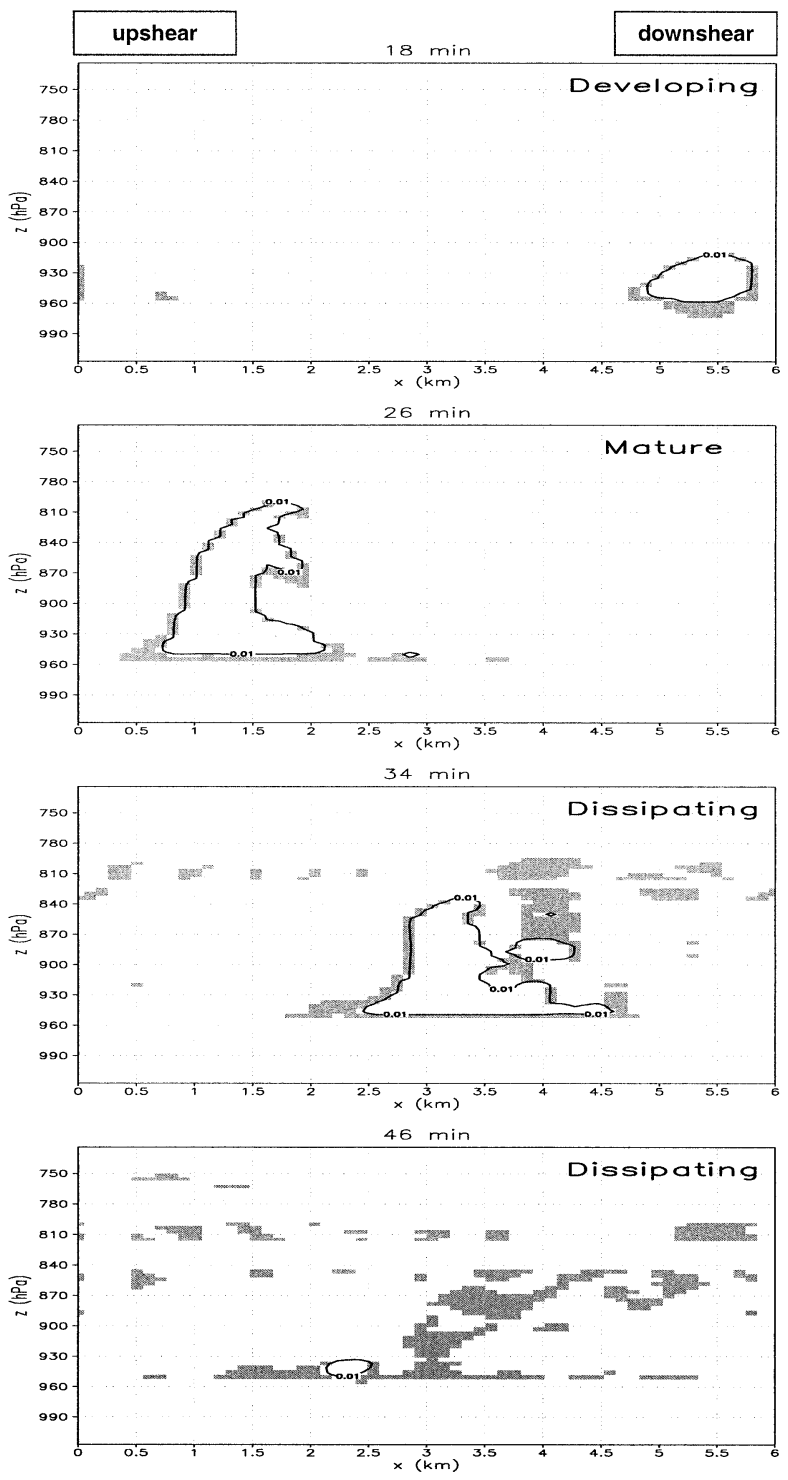

FIG. 10. Same as Fig. 4 but for the Barbados trade wind cumulus.

vironment. The results also suggest that a $3 \mathrm{D}$ radiative transfer calculation, rather than a plane-parallel or independent pixel approximation that assumes no horizontal photon transport, is required for assessing radiative impacts of the humidity halo. This is because significant numbers of photons are scattered from the adjacent cloud into the lateral halo region to enhance the net downward flux therein. The net downward flux averaged over the halo columns decreases below the cloud base because there is no enhancement through cloud scattering, leaving only the atmospheric gaseous absorption.

\section{b. SW heating rate}

From the radiative energy balance equation, it can be shown that the heating rate $H$ at an arbitrary point ( $x$, $y, z)$ can be related to the absorbed power-per-unit volume $\left(F_{a}\right)$ within the grid cell by

$$
H=-\frac{1}{\rho c_{p}} \boldsymbol{\nabla} \cdot \mathbf{F}(x, y, z)=\frac{1}{\rho c_{p}} F_{a}(x, y, z),
$$

where $\rho$ is air density, $\mathbf{F}$ is the radiative flux vector, and $c_{p}$ is specific heat of dry air. The net amount of photons accumulating in a grid cell can be estimated from the radiative heating rate, which is proportional to the divergence of the radiative flux by Eq. (7). The $x-z$ plot of the SW heating rate (Fig. 13, showing only the Hawaii case without wind) has a nonsymmetric pattern with a minimum in the direction opposite to that of the incoming solar radiation. The minimum is due to the large extinction by the cloud along the incoming solar path with a zenith angle of about $10^{\circ}$. The maximum heating rate can appear at both sides of the cloud for suitable combinations of the cloud shape, cloud depth, and solar zenith angle, as in this case. Other cases also show the same pattern as in Fig. 13. Because the solar zenith angle for the Barbados case is very close to zero, the heating rate minimum in the halo region covers a negligible area.

To understand the enhanced absorption in the humidity halo relative to the far-ambient absorption, we perform the same kind of averaging as in Fig. 11. The resulting profiles are shown in Fig. 14, displaying the time-averaged vertical profiles of the ambient and halo heating rates (averaged over the humidity halo columns, schematized in Fig. 12) for all cases. For the Oakland and Hawaii cases, the halo heating rate is larger than the ambient heating rate, except at the lowest levels. This is because of the minimum of the heating rate near the cloud base at the side opposite to the incoming solar radiation, as discussed above. There are two contributions to the increased halo heating (as illustrated in Fig. 2): (i) significant scattering of photons from the cloud edge, thus enhancing the net downward fluxes in the halo region as shown in Fig. 11, and (ii) enhanced water vapor absorption by the halo itself. The maximum difference between the time-averaged in-halo, and far-ambient heating rates for the Oakland case without wind is $0.0058 \mathrm{~K} \mathrm{~h}^{-1}$ at $900 \mathrm{hPa}$. In other words, the enhanced heating rate in the halo at that level amounts to approximately $11 \%$ of the far-ambient heating rate of $0.052 \mathrm{~K} \mathrm{~h}^{-1}$. The result for the sheared Oakland case (Fig. 14b) is similar to that for no wind (Fig. 14a); the maximum difference between the in-halo and far-ambient heating rates is $0.0065 \mathrm{~K} \mathrm{~h}^{-1}$ at $950 \mathrm{hPa}$, about $12 \%$ of the far-ambient heating rate of $0.055 \mathrm{~K} \mathrm{~h}^{-1}$. The enhanced halo heating rate occurs at higher levels for the Hawaii case (Figs. 14c,d) than for the Oakland case, because of a higher cloud base. The maximum difference between the two heating rates for the Hawaii case without wind (Fig. 14c) is $0.019 \mathrm{~K} \mathrm{~h}^{-1}$ at $788 \mathrm{hPa}$, about $16 \%$ of the far-ambient heating rate $0.12 \mathrm{~K} \mathrm{~h}^{-1}$. In the sheared Hawaii case (Fig. 14d), the larger and more significant humidity halo and the many small cloud patches lead to larger halo absorption; the 
(a)

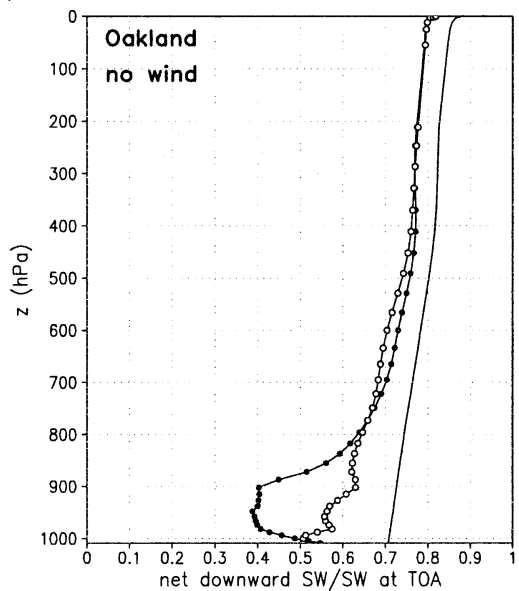

(c)

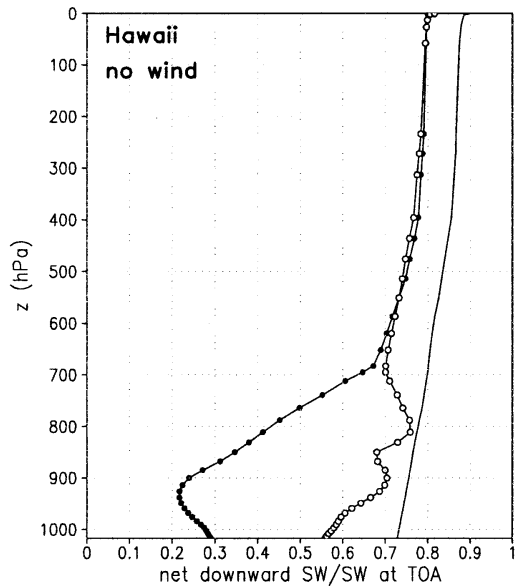

(e)

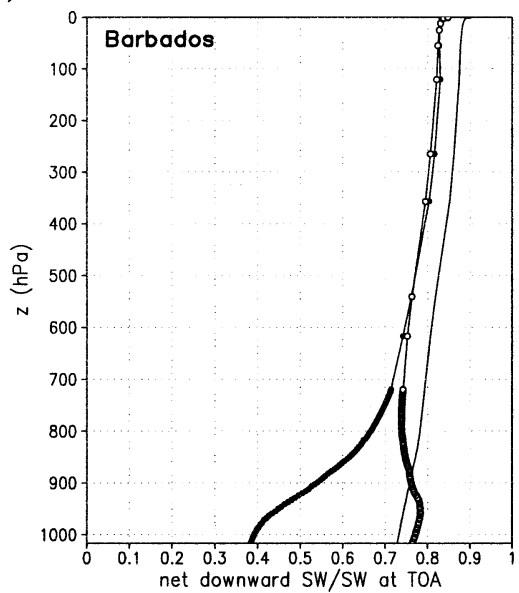

(b)

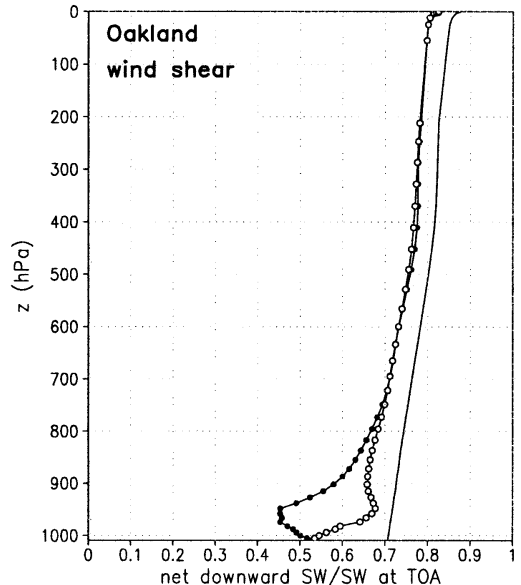

(d)

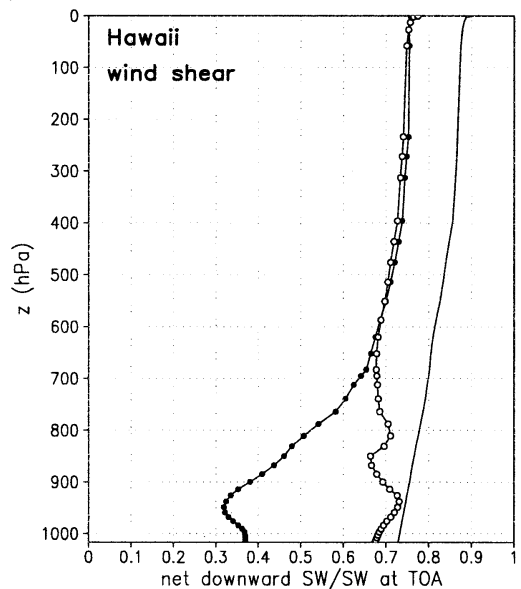

FIG. 11. Vertical profile of the temporally and spatially averaged net downward SW flux normalized to the incoming SW at the TOA for the cloud of the (a) Oakland case without wind (Fig. 4), (b) Oakland case with wind shear (Fig. 5), (c) Hawaii case without wind (Fig. 7), (d) Hawaii case with wind shear (Fig. 8), and (e) Barbados case (Fig. 10) for cloud (closed circle), halo (open circle), and farambient (solid line). The area average is illustrated in Fig. 12.

maximum enhancement of the heating rate in the humidity halo, relative to the far-ambient region, is 0.022 $\mathrm{K} \mathrm{h}^{-1}$ at $831 \mathrm{hPa}$, about $18 \%$ of the clear-sky heating rate of $0.12 \mathrm{~K} \mathrm{~h}^{-1}$. The Barbados case (Fig. 14e) exhibits a more uniform enhancement of the halo heating below $850 \mathrm{hPa}$ than do the other cases, because the solar zenith angle is close to zero. The maximum value of the timeaveraged halo heating rate enhancement is $0.013 \mathrm{~K} \mathrm{~h}^{-1}$ at $955 \mathrm{hPa}$, about $11 \%$ of the ambient heating rate of $0.12 \mathrm{~K} \mathrm{~h}^{-1}$.

In short, several factors can affect the humidity halo absorption, among them the cloud shape, cloud depth, 


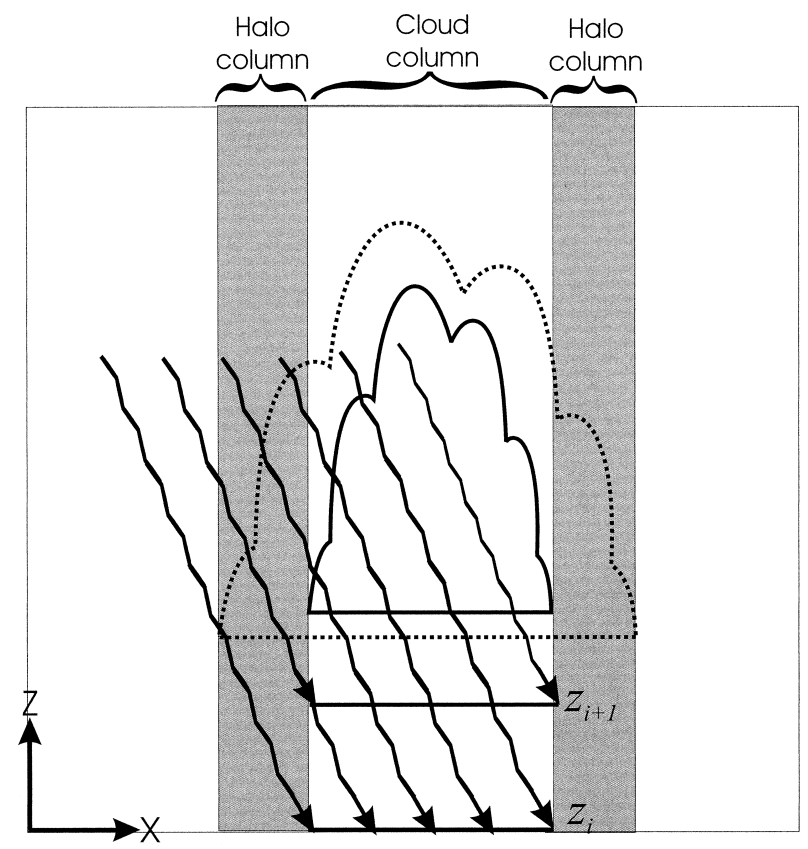

FIG. 12. Illustration of the increased net downward flux below cloud base (see text for details). The shaded columns are halo columns, and between them is the cloud column. The solid line is the cloud, and the region between the dotted line and the cloud defines the cloud halo. The two bold horizontal lines represent levels $z_{i}$ and $z_{i+1}$, with $z_{i+1}>z_{i}$.

3D halo distribution, and solar zenith angle. Factors other than the solar zenith angle cannot be simply determined before a simulation, making the humidity halo absorption a complex issue.

\section{c. Change of SW heating rate due to the halo}

One approach to assessing the radiative effect of the humidity halo region is to compare SW radiative heating rates in the presence and absence of the halo. The presence-of-halo scenario is chosen as the output from the RAMS model, and the absence-of-halo scenario is defined by replacing the water vapor field of the shaded regions in Figs. 4, 5, 7, 8, and 10 with the far-ambient values at the corresponding heights. Figure 15 shows the vertical profiles of this heating rate difference, temporally and spatially averaged, for each cloud considered. For the Oakland case without wind (Fig. 15a), the halo has a radiative effect between 890 and $990 \mathrm{hPa}$ with large positive values below $960 \mathrm{hPa}$, with the humidity halo being evident mainly at lower levels. However, for the Oakland case with wind shear (Fig. 15b), the radiative effect is pronounced between 900 and 990 $\mathrm{hPa}$, because the halo is more vertically extensive. The difference between the heating rates is negative below the halo area, as a result of absorption in the halo above. The Hawaii case without wind (Fig. 15c) shows two regions of significant positive time-averaged heating rate differences. The halo radiative effect is stronger at
TABLE 2. Temporally and spatially averaged halo SW radiative forcing at the surface of the earth. See section 3 for details of the location for each case.

\begin{tabular}{lcc}
\hline \hline Location & Wind condition & $\begin{array}{c}\text { Halo radiative } \\
\text { forcing }\left(\mathrm{W} \mathrm{m}^{-2}\right)\end{array}$ \\
\hline Oakland, CA & $\begin{array}{c}\text { No } \\
\text { Oakland, CA }\end{array}$ & -0.001 \\
Kauai, HI & Wind shear & -0.023 \\
Kauai, HI & No & -0.067 \\
Barbados & Wind shear & -0.190 \\
\hline
\end{tabular}

the lower levels than at the upper levels, consistent with the halo being correspondingly more persistent and broader at the lower levels. Another key point from this figure is that the halo radiative effect in the absence of wind is larger for the Hawaii case than for the Oakland case, because we can anticipate that stronger convection causes a broader and more humidified halo. In a sheared environment (Fig. 15d), the halo is both deeper and broader, especially during cloud dissipation, and the halo radiative effect is more significant than in the absence of wind (Fig. 15c). For the Barbados trade wind cumulus, the difference in heating rates (Fig. 15e) displays layers of positive values through 960-930 hPa and $870-800 \mathrm{hPa}$. The lower region of positive halo heating rate differences results from a thin layer of halo at the cloud base, whereas the humidity halo formed by the dissipation of upper portions of the cloud results in a large radiative effect at these upper levels. All of the case studies illustrate that the vertical distribution of the halo radiative effect is directly related to the vertical distribution of the halo. The Hawaii case in a sheared environment exhibits the largest time-averaged effect. Strong convection in a sheared environment, therefore, is a key factor in producing relatively broad and vertically extensive cloud halos with concomitant strong radiative effects.

\section{d. Halo radiative forcing at the surface of the earth}

We further calculate the halo-induced radiative forcing at the surface of the simulated domain. Halo-induced radiative forcing is defined by the difference between the radiative fluxes in the presence-of-halo scenario and in the absence-of-halo scenario. The boundary condition of the radiative transfer model is such that horizontal radiative transport of the domain is zero. Therefore, the radiative forcing can be estimated from only the net downward flux at the surface. The temporally and spatially averaged halo SW surface radiative forcing for all cases, given in Table 2 , shows all negative values, indicating that the presence of the halo can reduce the SW energy at the surface. The results also clearly demonstrate that this forcing is larger with wind shear than with no wind. The strongest forcing, for the Hawaii case with wind shear, is -0.19 $\mathrm{W} \mathrm{m} \mathrm{m}^{-2}$, which is approximately a $0.02 \%$ change when 
$18 \mathrm{~min}$

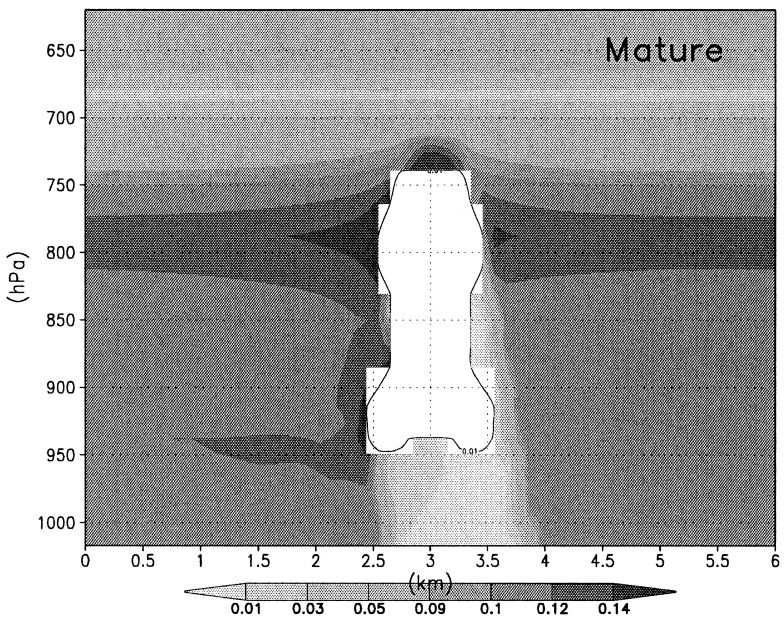

$42 \mathrm{~min}$

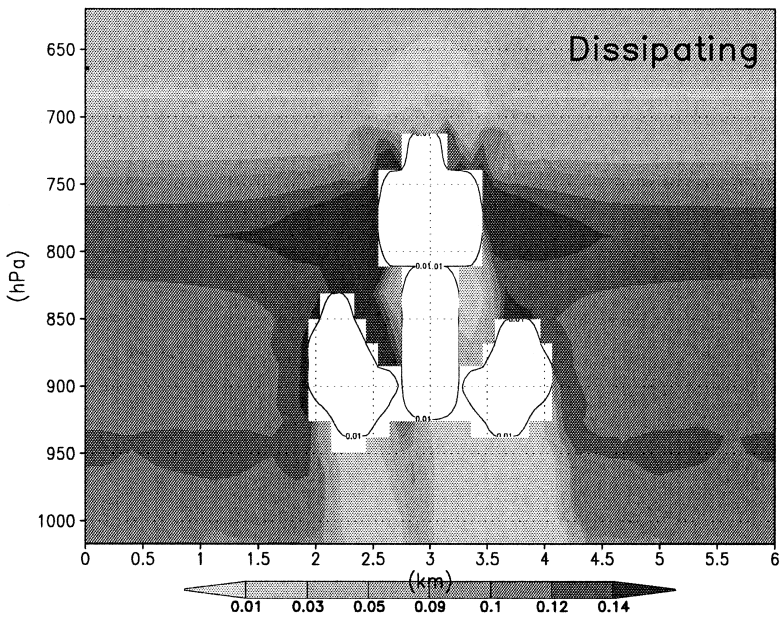

$30 \mathrm{~min}$

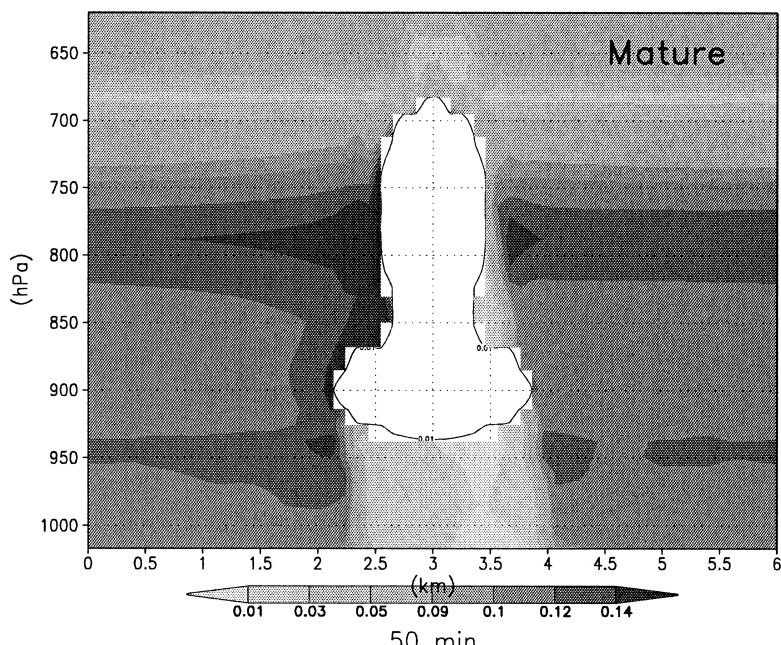

$50 \mathrm{~min}$

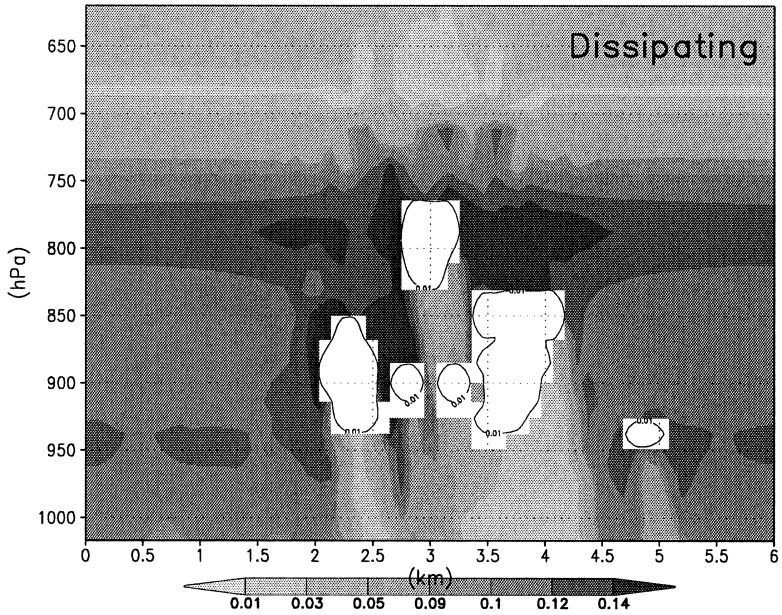

FIG. 13. The SW heating rate $\left(\mathrm{K} \mathrm{h}^{-1}\right)$ for the small cumulus of Fig. 7. In-cloud values are not shown in order to show details in the halo region. Cloud boundaries are defined by the $0.01 \mathrm{~g} \mathrm{~m}^{-3}$ contour line for the cloud LWC.

compared with no halo. The halo radiative effect is generally small when the cloud starts to form and becomes larger with time. Therefore, the results of the halo surface forcing are consistent with the conclusions in previous sections.

\section{Summary}

From our simulations of several cumulus cloud scenarios, we can conclude that the spatial distribution of cloud halos has the following common characteristics: 1) the humidity halo occurs primarily near the lateral cloud boundaries, as verified by many observations. When the upper (lower) portion of a cloud dissipates, it leaves behind a humidified area. 2) The humidity halo is broader in the presence of wind shear than in the absence of wind, and it broadens with cloud age. 3) The humidity halo is broader near the downshear cloud boundary than near the upshear side, owing to cumulus cloud dynamics that favor growth on the upshear side and decay on the downshear side. Evaporation of cloud droplets on the down- shear side humidifies the clear air there. However, the growth of new cumulus turrets limits the clear-air humidity modification on the upshear side.

The halo can absorb both incoming solar energy from the clear sky above and scattered SW radiation from the cloud, and hence it increases the total absorption in the domain. The $\mathrm{SW}(0.2-4.0 \mu \mathrm{m})$ radiative heating rate in the halo is $11 \%-18 \%$ larger than the ambient environmental heating rate. The strongest halo-induced surface SW radiative forcing, averaged temporally and spatially, among all cases studied is about $-0.19 \mathrm{~W} \mathrm{~m}^{-2}$, a $0.02 \%$ change as compared with no halo. The radiative effect of the halo is closely related to the cloud evolution. It is largest at cloud dissipation when the halo expands, as shown by the calculated net downward flux, heating rate, and surface radiative forcing.

Increased absorption due to the humidity halo depends on the amount of water vapor, cloud morphology, solar zenith angle, spatial halo distribution, incoming solar energy, cloud age, and the interaction of the environmental wind with the cloud evolution. 
(a)

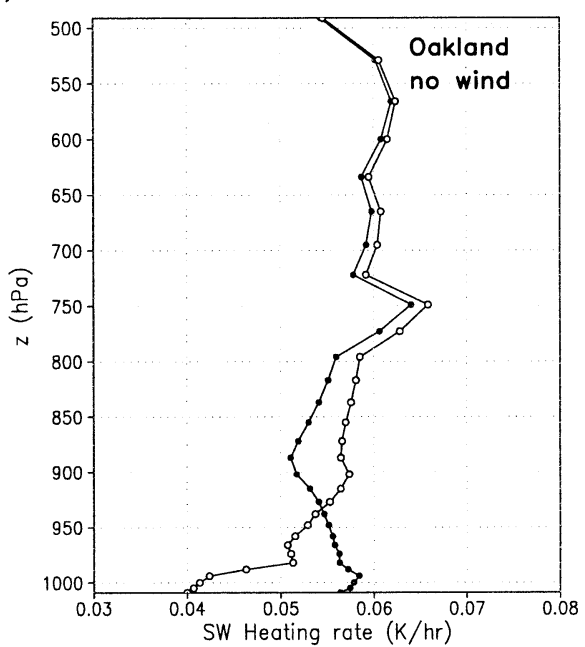

(c)

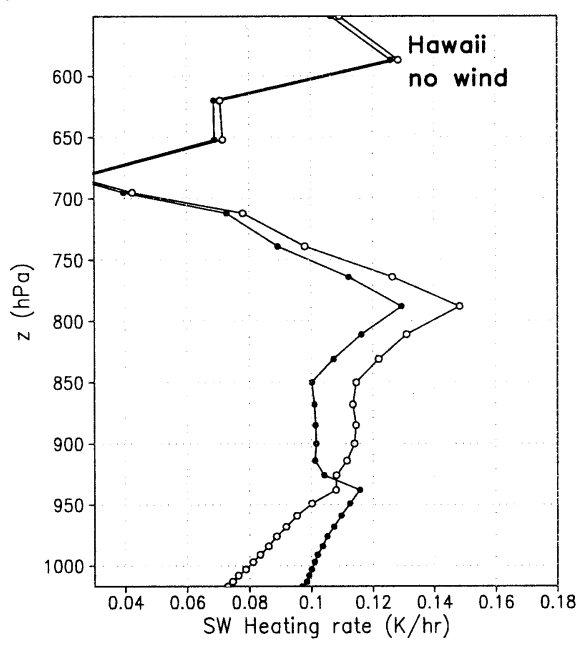

(e)

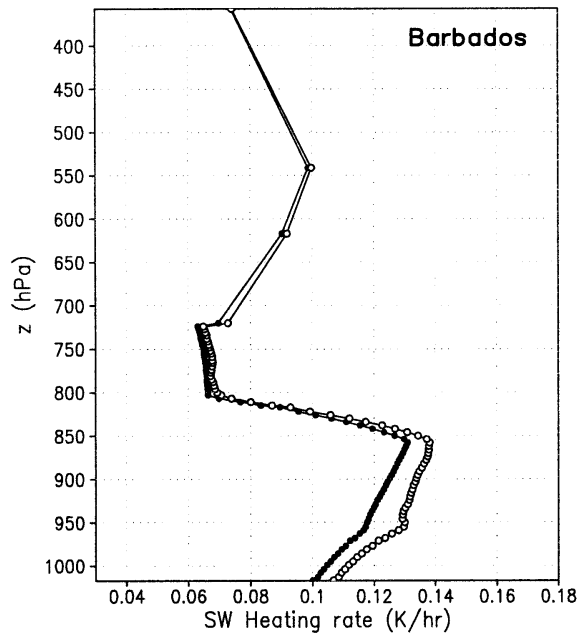

(b)

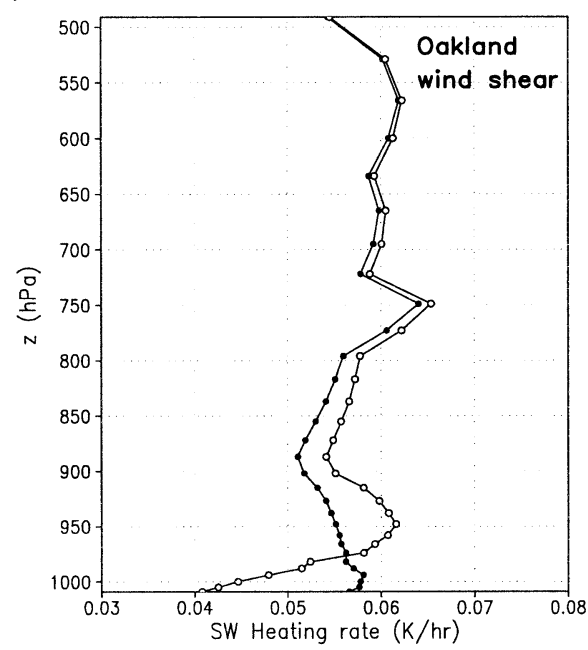

(d)

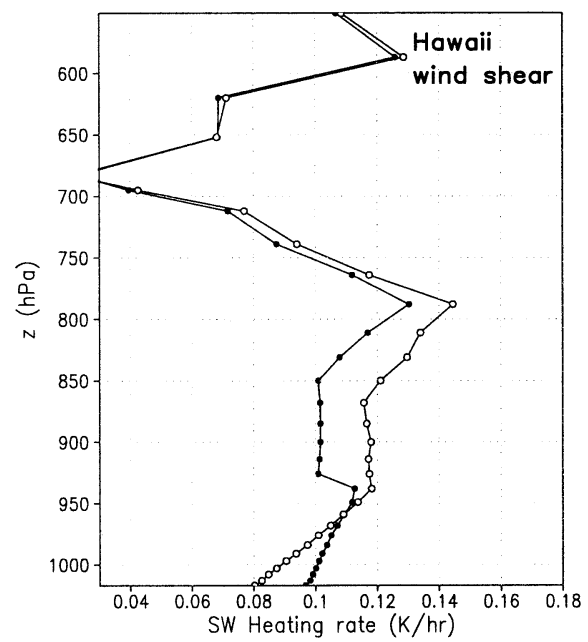

FIG. 14. Vertical profile of the temporally and spatially averaged SW heating rate for the cloud of the (a) Oakland case without wind (Fig. 4), (b) Oakland case with wind shear (Fig. 5), (c) Hawaii case without wind (Fig. 7), (d) Hawaii case with wind shear (Fig. 8), and (e) Barbados case (Fig. 10) for halo (open circle) and far-ambient (closed circle). 
(a)

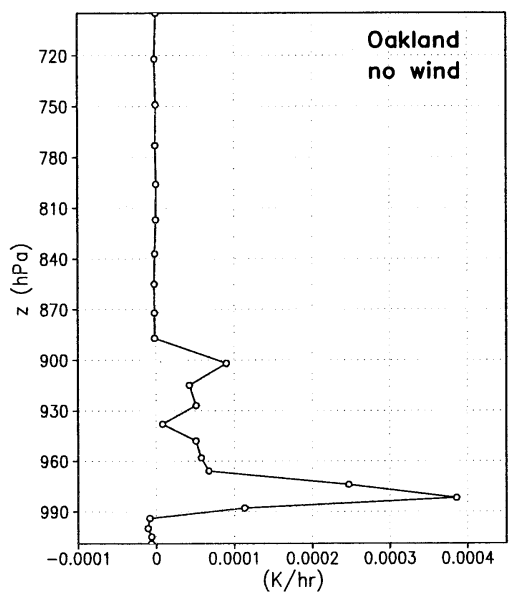

(c)

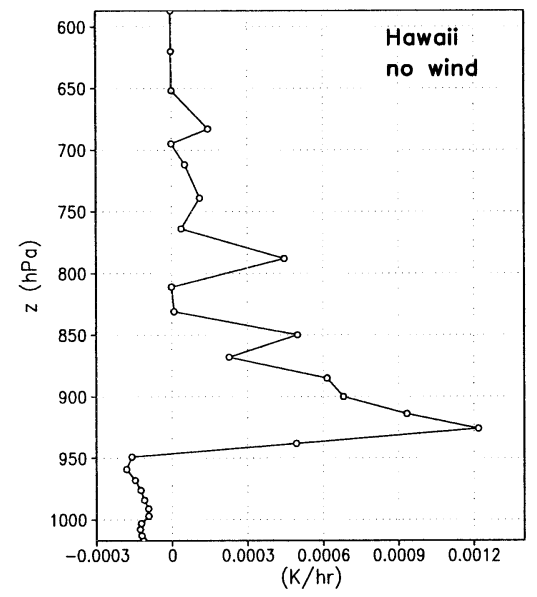

(e)

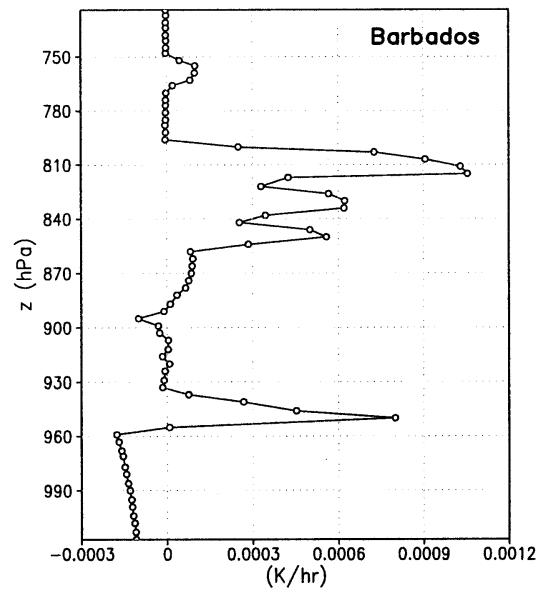

Acknowledgments. We thank Prof. Frank Evans at the University of Colorado for providing and helping with the SHDOM model. Constructive reviews from anonymous reviewers helped in the presentation of this paper. This work was supported by National Science Foundation Grant ATM-9907010. (b)

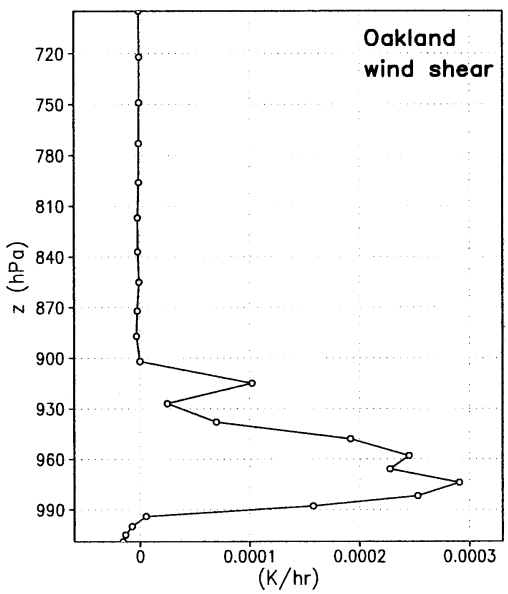

(d)

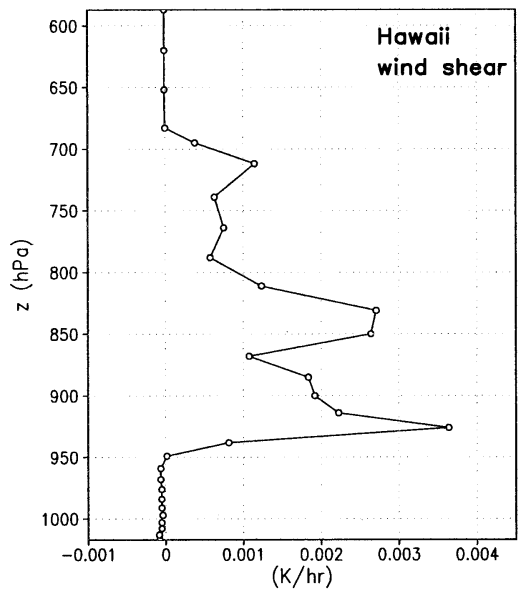

FIG. 15. The radiative effect of the cloud halo, computed by subtracting the domain-averaged heating rate in the presence of the halo from that in the absence of the halo, for the (a) Oakland case without wind, (b) Oakland case with wind shear, (c) Hawaii case without wind, (d) Hawaii case with wind shear, and (e) Barbados case. These heating rate profiles are temporally averaged over the cloud lifetime and are spatially averaged over the horizontal domain.

\section{REFERENCES}

Ackerman, B., 1958: Turbulence around tropical cumuli. J. Meteor. 15, 69-74.

Arking, A., 1996: Absorption of solar energy in the atmosphere: Discrepancy between model and observations. Science, 273, 779-782. 
Austin, G. R., R. M. Rauber, H. T. Ochs III, and L. J. Miller, 1996: Trade-wind clouds and Hawaiian rainbands. Mon. Wea. Rev. 124, 2126-2151.

Bretherton, C. S., and P. K. Smolarkiewicz, 1989: Gravity waves, compensating subsidence and detrainment around cumulus clouds. J. Atmos. Sci., 46, 740-759.

Chen, Y.-L., and A. Nash, 1994: Diurnal variation of surface airflow and rainfall frequencies on the island of Hawaii. Mon. Wea. Rev $122,34-56$.

Chylek, P., and V. Ramaswamy, 1982: Simple approximation for infrared emissivity of water clouds. J. Atmos. Sci., 39, 171-177.

Crisp, D., 1997: Absorption of sunlight by water vapor in cloudy conditions: A partial explanation for the cloud absorption anomaly. Geophys. Res. Lett., 24, 571-574.

Davidson, B., 1968: The Barbados Oceanographic and Meteorological Experiment. Bull. Amer. Meteor. Soc., 49, 928-934.

Davies, R., W. L. Ridgway, and K.-E. Kim, 1984: Spectral absorption of solar radiation in cloudy atmosphere: A $20 \mathrm{~cm}^{-1}$ model. $J$. Atmos. Sci., 41, 2126-2137.

Deardorff, J. W., 1970: A numerical study of three-dimensional turbulent channel flow at large Reynolds number. J. Fluid Mech. 41, 453-480.

Evans, K. F., 1993: Two-dimensional radiative transfer in cloudy atmospheres: The spherical harmonic spatial grid method. $J$. Atmos. Sci., 50, 3111-3124.

_, 1998: The spherical harmonic discrete ordinate method for three-dimensional atmospheric radiative transfer. J. Atmos. Sci., 55, 429-446.

Fu, Q., and K. N. Liou, 1992: On the correlated $k$-distribution method for radiative transfer in nonhomogeneous atmospheres. J. Atmos. Sci., 49, 2139-2156.

GEWEX, 2000: GEWEX Global Cloud System Study (GCSS) Second Science and Implementation Plan. Int. GEWEX Project Office Series, Vol. 34, GEWEX, $52 \mathrm{pp}$.

Harrington, J. Y., 1997: The effects of radiative and microphysical processes on simulated warm and transition season arctic stratus. Ph.D. dissertation, Dept. of Atmospheric Science, Colorado State University, $289 \mathrm{pp}$.

Hobbs, P. V., and L. F. Radke, 1992: Reply. J. Atmos. Sci., 49, 15161517.

Jiang, H., and W. R. Cotton, 2000: Large eddy simulation of shallow cumulus convection during BOMEX: Sensitivity to microphysics and radiation. J. Atmos. Sci., 57, 582-594.

Kogan, Y. L., 1991: The simulation of a convective cloud in a 3-D model with explicit microphysics. Part I: Model description and sensitivity experiments. J. Atmos. Sci., 48, 1160-1189.

Kollias, P., B. A. Albrecht, R. Lhermitte, and A. Savtchenko, 2001: Radar observations of updrafts, downdrafts, and turbulence in fair-weather cumuli. J. Atmos. Sci., 58, 1750-1766.

Li, J., and Y.-L. Chen, 1999: A case study of nocturnal rain showers over the windward coastal region of the island of Hawaii. Mon. Wea. Rev., 127, 2674-2692.

Li, Z., and A. P. Trishchenko, 2001: Quantifying uncertainties in determining SW cloud radiative forcing and cloud absorption due to variability in atmospheric conditions. J. Atmos. Sci., 58, 376-389.

Malkus, J. S., 1949: Effects of wind shear on some aspects of convection. Trans. Amer. Geophys. Union, 30, 19-25.

_ 1954: Some results of a trade-cumulus investigation. J. Meteor. 11, 220-237.

McClatchey, R. A., R. W. Fenn, J. E. A. Selby, P. E. Volz, and J. S. Garing, 1972: Optical Properties of the Atmosphere. 3d ed. Air Force Cambridge Research Laboratory AFCRL-72-0497, 113 pp.

Nakajima, T., and M. Tanaka, 1988: Algorithms for radiative intensity calculations in moderately thick atmospheres using a truncation approximation. J. Quant. Spectrosc. Radiat. Transfer, 40, 5169.

O'Hirok, W., and C. Gautier, 1998: A three-dimensional radiative transfer model to investigate the solar radiation within a cloudy atmosphere. Part I: Spatial effects. J. Atmos. Sci., 55, 21622179.

Perry, K. D., and P. V. Hobbs, 1996: Influences of isolated cumulus clouds on the humidity of their surroundings. J. Atmos. Sci., 53, $159-174$.

Pielke, R. A., and Coauthors, 1992: A comprehensive meteorological modeling system-RAMS. Meteor. Atmos. Phys., 49, 69-91.

Podgorny, I. A., A. M. Vogelmann, and V. Ramanathan, 1998: Effects of cloud shape and water vapor distribution on solar absorption in the near infrared. Geophys. Res. Lett., 25, 1899-1902.

Radke, L. F., and P. V. Hobbs, 1991: Humidity and particle fields around some small cumulus clouds. J. Atmos. Sci., 48, 11901193.

Takahashi, T., 1977: A study of Hawaiian warm rain showers based on aircraft observation. J. Atmos. Sci., 34, 1733-1790.

Telford, J. W., and P. B. Wagner, 1980: The dynamical and liquid water structure of the small cumulus as determined from its environment. Pure Appl. Geophys., 118, 935-952.

Trautmann, T., I. Podgorny, J. Landgraf, and P. J. Crutzen, 1999: Actinic fluxes and photodissociation coefficients in cloud fields embedded in realistic atmospheres. J. Geophys. Res., 104, 30 173-30192.

Tripoli, G. J., and W. R. Cotton, 1981: The use of ice-liquid water potential temperature as a thermodynamic variable in deep atmospheric models. Mon. Wea. Rev., 109, 1094-1102.

Walko, R. L., W. R. Cotton, M. P. Meyers, and J. Y. Harrington, 1995 New RAMS cloud microphysics parameterization. Part I: The single-moment scheme. Atmos. Res., 38, 29-62.

Wang, J.-J., and Y.-L. Chen, 1998: A case study of trade-wind rainbands and their interaction with the island-induced airflow. Mon Wea. Rev., 126, 409-423.

Warner, J., 1977: Time variation of updraft and water content in small cumulus clouds. J. Atmos. Sci., 34, 1306-1312.

Wendisch, M., and A. Keil, 1999: Discrepancies between measured and modeled solar and UV radiation within polluted boundary layer clouds. J. Geophys. Res., 104, 27 373-27 385. 